\title{
Postsynaptic, but Not Presynaptic, Activity Controls the Early Time Course of Long-term Potentiation in the Dentate Gyrus
}

\author{
Eric Hanse and Bengt Gustafsson \\ Department of Physiology, University of Göteborg, S-413 90 Göteborg, Sweden
}

The early time course ( $<1 \mathrm{hr}$ ) of long-term potentiation (LTP) in the dentate gyrus of the guinea pig hippocampal slice was examined using extracellular recordings from the outer twothirds of the dendritic layer. LTP was induced by a single brief (2-40 impulses) high-frequency $(20-400 \mathrm{~Hz}$ ) train, or by pairing a single test stimulus with a brief heterosynaptic high-frequency train. The induction of LTP was facilitated by blockade of fast GABAergic postsynaptic inhibition. It was found that, irrespective of induction conditions and the amount of LTP induced, the onset of LTP was characterized by a latency of a few seconds following the induction event, and a rapid $30 \mathrm{sec}$ growth phase. After a 1-2 min period of little or no further growth, LTP decayed but in a highly variable manner, from cases in which more than $60 \%$ of the peak value remained $1 \mathrm{hr}$ after the induction to cases in which LTP decayed completely within $10 \mathrm{~min}$. Factors increasing presynaptic activity (frequency or number of afferent stimulations) during the induction event did not affect the relative amount of LTP decay. Repetitive presynaptic activity was found not to be a necessary condition for eliciting long-lasting LTP ( $>1 \mathrm{hr}$ ), as shown by experiments in which a single presynaptic impulse was paired with a brief heterosynaptic train. Factors increasing postsynaptic activity during the induction event, such as increased stimulus intensity, temporal pairing of two weak trains, or reduced postsynaptic inhibition, all reduced the relative amount of LTP decay. Moreover, partial pharmacological blockade of NMDA receptor channels increased the relative amount of decay. In conclusion, the amount of postsynaptic activity and associated NMDA receptor activation during the induction event appeared to be the main factor governing the early stability of LTP in the dentate gyrus.

Long-term potentiation (LTP) is a long-lasting increase in synaptic efficacy that is generally believed to be involved in learning and memory in the mammalian brain (Teyler and Discenna, 1984; McNaughton and Morris, 1987). LTP was first described in vivo for the excitatory synaptic connections between perforant path afferents and granule cells in the molecular layer of the dentate gyrus (Lömo, 1966; Bliss and Lömo, 1973), and has subsequently been described and characterized in other areas

\footnotetext{
Received Jan. 3, 1992; revised Mar. 12, 1992; accepted Mar. 23, 1992.

Correspondence should be addressed to E. Hanse, Department of Physiology, University of Göteborg, P.O. Box 33031, S-41390 Göteborg, Sweden.

This work was supported by the Swedish Medical Research Council (Project 05180 ), the foundation of Magnus Bergvall, and Svenska Sällskapet för Medicinsk Forskning.
}

Copyright $\odot 1992$ Society for Neuroscience $0270-6474 / 92 / 123226-15 \$ 05.00 / 0$ of the hippocampal formation as well as in other cortical regions (for references, see Kuba and Kumamoto, 1990). It appears, however, that LTP in various regions is not one and the same process, but may differ with respect to induction, expression, or maintenance (e.g., Harris and Cotman 1986; Alonso et al., 1990; Zalutsky and Nicoll, 1990; Sah and Nicoll, 1991).

LTP has been most extensively studied in the dentate gyrus and in the CA 1 region of the hippocampal formation, and is in both regions believed to be induced by calcium influx through postsynaptic NMDA receptor channels (Morris et al., 1986; Wigström et al., 1986; Errington et al., 1987; Malenka et al., 1989). However, the question has been raised as to whether the calcium influx triggers the same biochemical events and the same types of synaptic modifications in the two regions (Linden and Routtenberg, 1989; Kuba and Kumamoto, 1990), variations that may result in differences in the temporal characteristics of LTP, and how these are controlled. It has in fact been suggested that LTP in the dentate gyrus and in the CAl region should differ from each other with respect to temporal characteristics due to variations in information processing between these two regions (McNaughton and Barnes, 1990).

In the CAl region, the temporal development of LTP has been examined under various induction conditions after procedures that eliminated the influence of short-lasting potentiation processes, such as augmentation (Gustafsson et al., 1989). The present study adopts the same procedures to investigate the early time course of LTP in the dentate gyrus and to see how this time course compares to that in the CA1 region.

\section{Materials and Methods}

Preparation of slices. Experiments were performed on hippocampal slices from 83 guinea pigs weighing $250-450 \mathrm{gm}$ and of either sex. The animals were deeply anesthetized with ethyl ether, and their brains were removed. The left hippocampus was dissected out, and $400-\mu \mathrm{m}$-thick slices from the middle portion were cut perpendicular to the septotemporal axis. The slices were kept half-submerged on a nylon net in a constant-flow $(2.5 \mathrm{ml} / \mathrm{min})$ chamber. The perfusion fluid consisted of (in $\mathrm{mM}$ ): $\mathrm{NaCl}, 124 ; \mathrm{KCl}, 4 ; \mathrm{CaCl}_{2}, 4 ; \mathrm{MgCl}_{2}, 4 ; \mathrm{NaHCO}_{3}, 26 ; \mathrm{NaH}_{2} \mathrm{PO}_{4}$, 1.25 ; glucose, 10 ; picrotoxin, 0.1 ; gassed with $95 \% \mathrm{O}_{2}, 5 \% \mathrm{CO}_{2}$. The slices were incubated for $2-3 \mathrm{hr}$ in room temperature before data were collected, and the chamber temperature was then held at $30^{\circ} \mathrm{C}$. The perfusion fluid contained picrotoxin in order to facilitate LTP induction via block of $\mathrm{GABA}_{\mathrm{A}}$-mediated inhibition, and higher than normal concentrations of calcium and magnesium were used to reduce the excitability increase during blockade of inhibition. Drugs were applied to the perfusion fluid or by droplets on the surface of the slice.

Extracellular recording of synaptic responses. Dentate granule cells were synaptically activated by electrical stimulation in the molecular layer (upper, suprapyramidal, blade of the dentate gyrus; Fig. 1A). Stimuli consisted of $0.1 \mathrm{msec}$ negative constant-current $(20-100 \mu \mathrm{A})$ pulses delivered through electrolytically sharpened tungsten wires (monopolar stimulation). Recordings of field potentials were made in the molecular layer by means of glass pipettes filled with $3 \mathrm{M} \mathrm{NaCl}$ (resistances between 
A
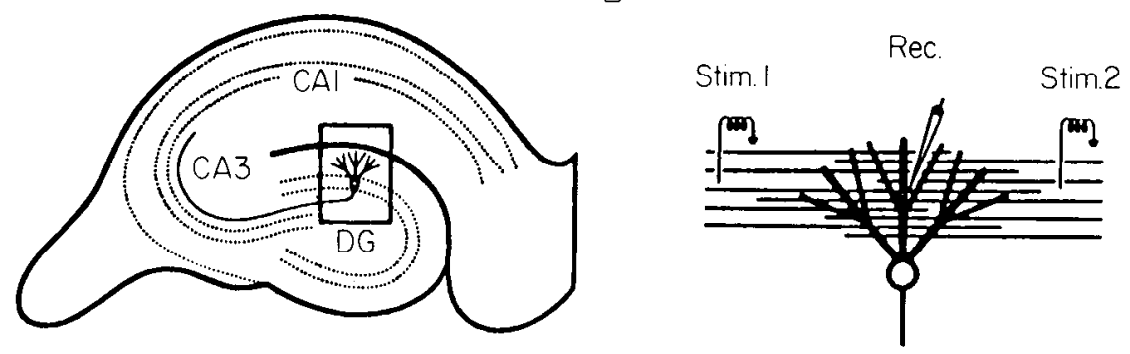

C

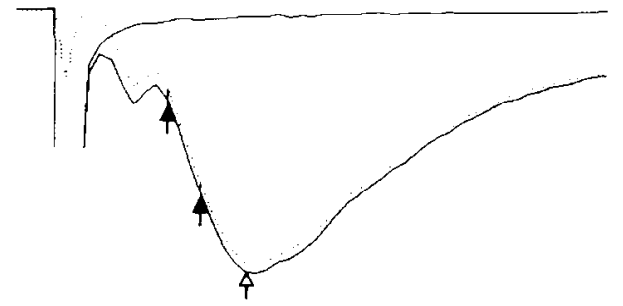

D
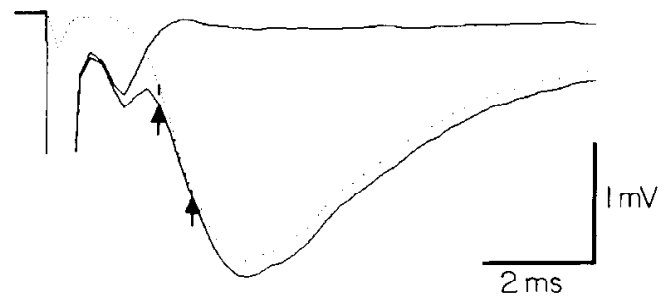

Figure 1. Placement of electrodes, and measurcments of ficld potentials. $A$, Schematic drawing of the hippocampal slice with studied area of the dentate gyrus boxed. $B$, Schematic drawing showing the arrangement of stimulating (Stim.) and recording $(R e c$.) electrodes. $C$, Average recording $(n=20)$ of field EPSP and its corresponding shock artifact in isolation. The shock artifact in isolation was obtained by strong $(10 \times$ test intensity), repeated (10-20 times) tetanization $(40-100$ impulses, $100 \mathrm{~Hz})$. The "true" field EPSP was obtained after subtraction of the shock artifact from the field EPSP and is represented by the broken line. Solid arrows indicate time window for estimation of the field EPSP initial slope. The amplitude was measured from the baseline preceding the field EPSP to an average value near the maximal amplitude of the field EPSP (open arrow). $D$, Field EPSP (same as in $C)$ and the effect of DNQX $(5 \mathrm{mM}$, drop application). The broken line represents the difference between the waveforms before and after DNQX application. Arrows indicate time window for estimation of the field EPSP initial slope.
$\mathrm{I}$ and $4 \mathrm{M} \Omega$ ). Field potentials were digitized $(5 \mathrm{kHz})$ and averaged for on-line and later off-line analysis by a laboratory minicomputcr.

Experimental procedure. Two stimulation electrodes were positioned under visual guidance to obtain stimulation of two independent afferent inputs. In most experiments, the stimulation electrodes were placed on either side of the recording electrode (Fig. 1B). The distance between the three electrodes and the granule cell layer was either approximately $150 \mu \mathrm{m}$ (middle third of the molecular layer) or $300 \mu \mathrm{m}$ (outer third of the molecular layer). The distance between the stimulation electrodes was $500-1000 \mu \mathrm{m}$. The independence and convergence of the two inputs were tested (at both test and twice test stimulation intensity; see below) by comparing the algebraical sum of the potentials evoked from the two inputs separately with the compound potential evoked from the two inputs simultaneously (Wigström and Gustafsson, 1985b). In some of the experiments one pair of electrodes (stimulation and recording) was placed in the outer third while another pair of electrodes was placed in the middle third of the molecular layer. Electrodes positioned in the outer and middle third of the molecular layer are likely to activate afferents belonging to lateral and medial perforant path, respectively. Previous studies have established that these afferent systems differ, for example, with respect to presynaptically related postactivation facilitations such as paired-pulse facilitation and augmentation (McNaughton, 1980). As will be described in a forthcoming publication, we observed no essential difference between characteristics of LTP obtained by stimulation of these two afferent systems, and they have therefore not been treated separately in this study.

Both inputs received a test stimulus every $2 \mathrm{sec}$ but $1 \mathrm{sec}$ apart. For tetanic activation, $100 \mathrm{~Hz}$ trains of impulses were used if not otherwise indicated. Stimulation intensity was set somewhat below that eliciting signs of spike activity in the dendritic field potential (test stimulation intensity). When examined using a separate recording electrode in the cell body layer $(n=11)$, signs of spike activity in the dendritic field potential were well correlated with the appearance of a population spike in the cell body layer recording. Twice test intensity during tetanic activation was achieved either via twice pulse duration or twice the amperage.

Data analysis. The field EPSP was measured both as the slope of its rising phase, hy means of linear regression of the first $0.6 \mathrm{msec}$ succeeding the presynaptic volley (Fig. $1 C$, solid arrows), and as the maximal amplitude (Fig. $1 C$, open arrow). Figure $1 C$ shows a field potential, a shock artifact in isolation (see legend, Fig. 1), and the field potential after subtracting the shock artifact (broken line). Due to the influence of the shock artifact, there was a slight underestimation of the field EPSP slope $(4.5 \pm 0.6 \% ; n=20)$ and a slight overestimation of the field EPSP amplitude $(4.3 \pm 0.3 \% ; n=20)$ [an increase of the field EPSP of $100 \%$ will thus be $105 \%$ measured with the slope and $96 \%$ measured with the amplitude (see, e.g., Fig. $4 B 3, B 4$ )]. Figure $1 D$ shows the field potential (same as in Fig. $1 C$ ) before and after application of the non-NMDA receptor antagonist 6,7-dinitroquinoxaline-2,3-dione (DNQX; $5 \mathrm{mM}$, drop application), and the difference between them (Fig. $1 C$, broken line). It can be noted that DNQX virtually abolishes the field EPSP and that the field EPSP starts already at the peak of the presynaptic volley.

The rationale for using only the first $0.6 \mathrm{msec}$ succeeding the presynaptic volley for the slope measurement (which gives rise to more noise) was to avoid measuring (1) spike activity, (2) any possible NMDA receptor-mediated synaptic component (Dahl et al., 1990; Lambert and Jones, 1990), and (3) a nonassociative potentiation, distinct from LTP, which is seen as an increase of the field EPSP that is restricted to parts succeeding the carly part of the initial slope (Hanse et al., 1991; see also Fig. $3 B$ ). Fast disynaptic ipsps were not expected to interfere with the measurements since picrotoxin was present in the perfusion fluid.

Each experiment began with a 10-20 min stable baseline, and values presented from single experiments are expressed as percentages of baseline values. Average values in the text and average time course curves are presented as relative change \pm SEM. Field EPSP amplitude measurements were used as a less noisier complement for the estimation of the growth phase of LTP. In those cases, care was taken to minimize the influence of the nonassociative potentiation either by saturating it (see Fig. 3) and/or by using a subthreshold induction strength for this potentiation (see Fig. 4). Statistical significance for paired and independent samples was evaluated using Student's $t$ test, and $P<0.05$ was required for statistical significance.

Drugs and chemicals. Picrotoxin was obtained from Sigma Co.; 6,7dinitroquinoxaline-2,3-dione (DNQX) and D-2-amino-5-phosphonovalerate (APV), from Tocris Neuramin.

\section{Results}

\section{LTP induced by single volley conjunction}

In the CAl region, the early time course of LTP could be obtained in isolation from short-term potentiation processes, such as augmentation, by using a single-volley conjunction procedure (Gustafsson and Wigström, 1986; Gustafsson et al., 1989). Figure $2 A$ illustrates that LTP can be evoked in this manner also in the dentate gyrus, and thus that its time course can be de- 


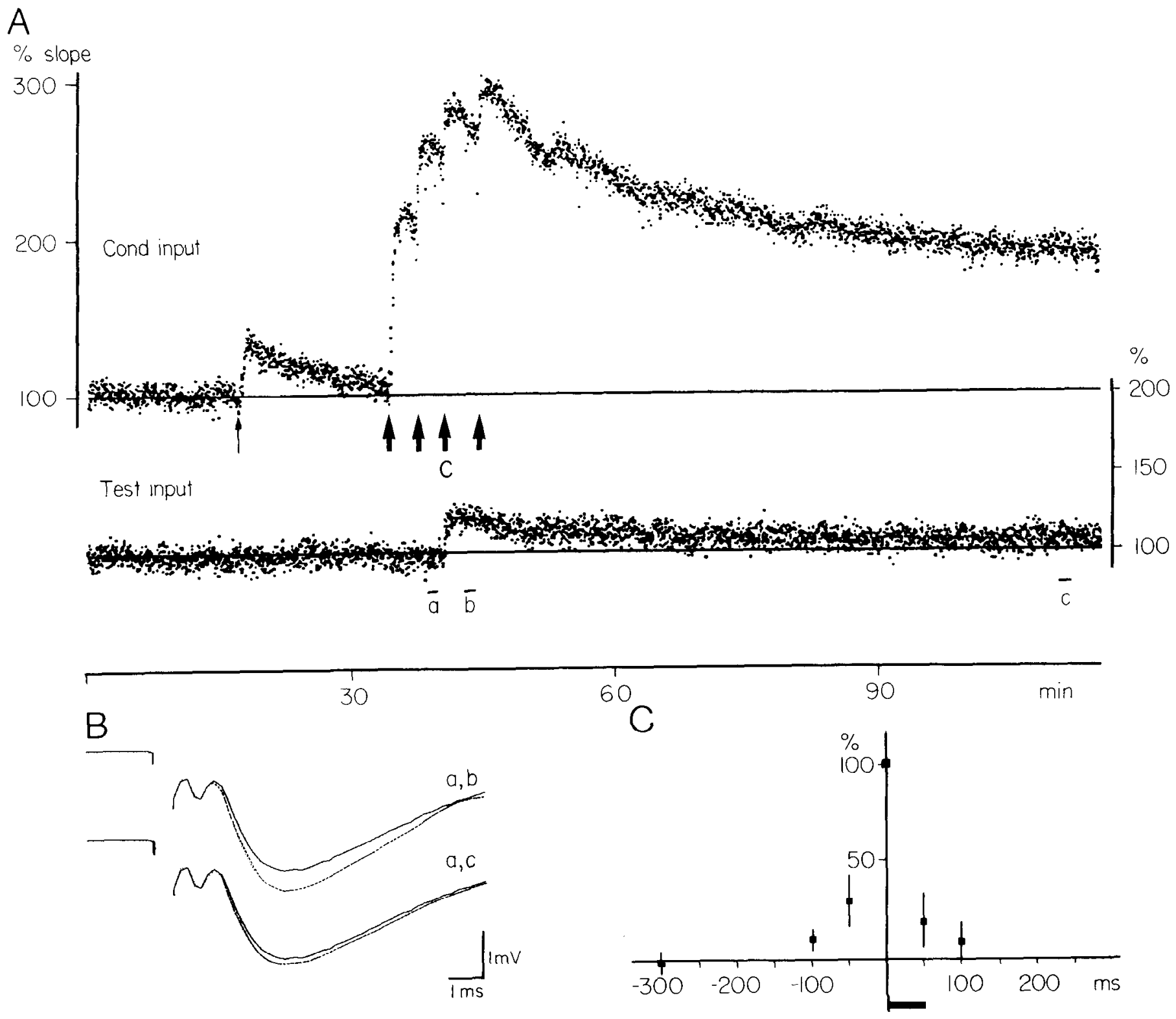

Figure 2. LTP induced by pairing a single test stimulus to one set of afferents with a brief conditioning tetanus to a separate set of afferents. $A$, Measurements of the initial slopes of the field EPSPs resulting from alternate activation of the test input (Test) and the conditioning input (Cond) are shown for a series of responses. The values are plotted as percentages of baseline values for each input. The conditioning input was tetanized at times indicated by arrows. The first tetanization ( 5 impulses, $100 \mathrm{~Hz}$; thin arrow) was delivered at test intensity (for purposes not relevant for the present context), while the remaining four wcre delivered at twice test intensity (thick arrows), and began 300 msec after, $100 \mathrm{msec}$ before, 5 msec after (conjunction, arrow labeled $C$ ), and $300 \mathrm{msec}$ after a test stimulation, respectively. $B$, Average records $(n=20)$ of test responses, taken at times indicated in $A(a-c)$. Records obtained after conjunction are shown as broken curves. $C$, Diagram showing relative amount of peak potentiation of the test field EPSP slope following a conditioning heterosynaptic tetanus (five impulses, $100 \mathrm{~Hz}$, twice test intensity) delivered at various test-conditioning intervals. The duration of the conditioning tetanus is schematically indicated by a horizontal bar. Time $=0$ indicates that the test stimulus and the conditioning tetanus were delivered simultaneously (conjunction), and negative values indicate that the test stimulus preceded the onset of the conditioning tetanus. In each experiment one or two long test-conditioning intervals were tested before conjunction was tested. The potentiation following each pairing event was expressed as percentage of the potentiation obtained with conjunction in that experiment. The results were obtained from 11 experiments (nine animals), and values are expressed as means \pm SD.

termined in isolation. Two independent inputs (in this case the stimulation electrodes were positioned in the middlc and outer third of the molecular layer, respectively; see also Materials and Methods) were activated alternately at $0.5 \mathrm{~Hz}$. each, and the single-volley stimulation of the test afferents was paired four times (Fig. $2 A$, thick arrows) with a single five-impulse tetanus (at twice test intensity) to the conditioning afferents at test- conditioning intervals of $-300 \mathrm{msec},+100 \mathrm{msec},-5 \mathrm{msec}$, and $-300 \mathrm{msec}$. As can be noted, a potentiation of the initial slope of the test EPSP was observed only with the short-interval pairing (conjunction, arrow labeled "C"), as expected for LTP (see also Fig. 2C). The conjunction-induced potentiation was quite long lasting even after a single event. In five experiments in which the potentiation was followed for more than $1 \mathrm{hr}$, the 

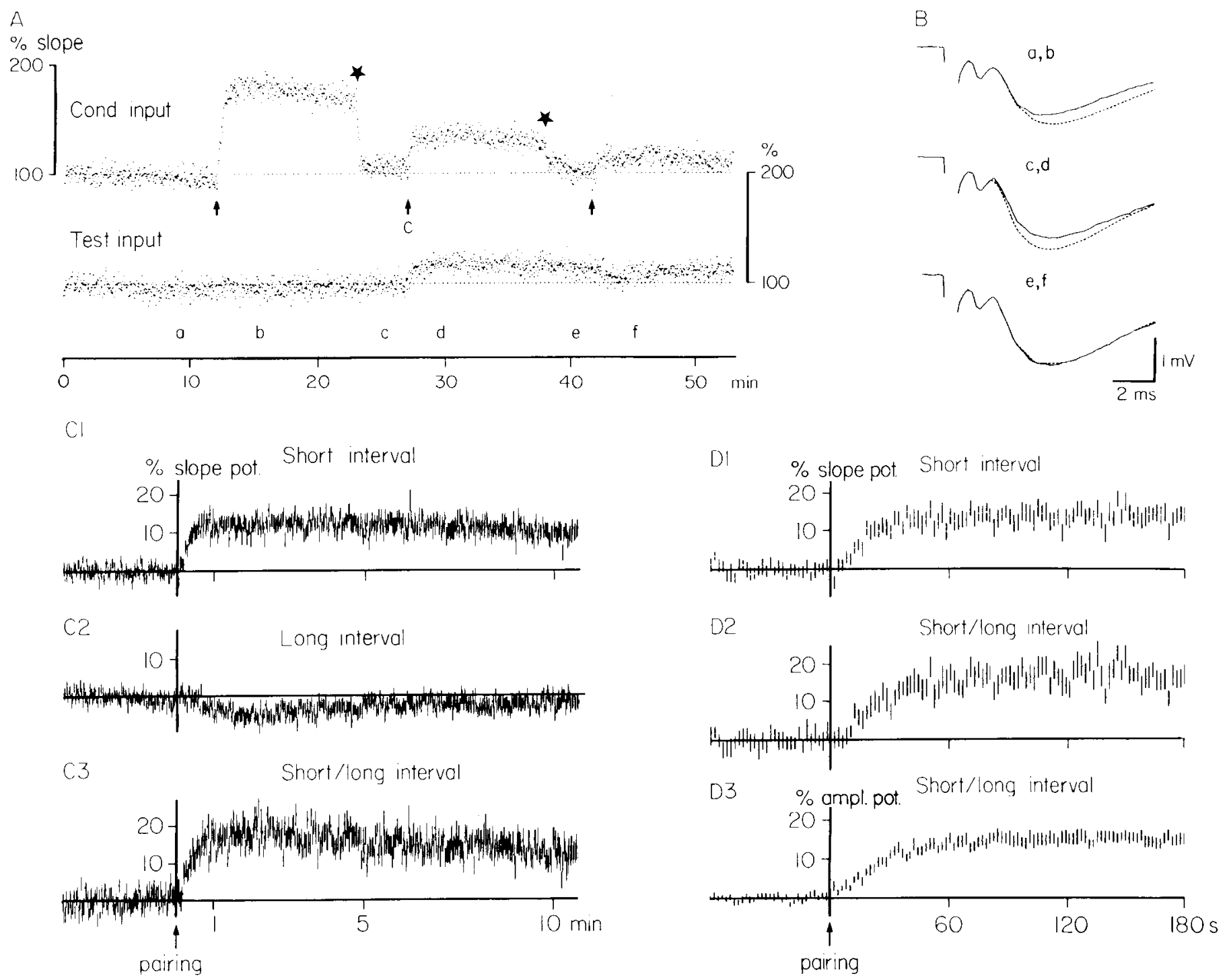

Figure 3. Early time course of conjunction-induced LTP. A, Measurements of the initial slope of the field EPSPs resulting from alternate activation of the test input and the conditioning input are shown for a series of responses. The values are plotted as percentages of baseline values. The conditioning input was tetanized (five impulses, $100 \mathrm{~Hz}$, twice test intensity) three times as indicated by arrows. The first and the third tetani were delivered $300 \mathrm{msec}$ after a test stimulation, while the second (arrow labeled $C$ ) was delivered $5 \mathrm{msec}$ after a test stimulus. Stars indicate reduction in stimulus intensity. $B$, Average records $(n=20)$ of test responses, taken at times indicated in $A(a-f)$. Records obtained after pairing are shown as broken curves. $C$. Average field EPSP slope changes ( $\pm \mathrm{SEM} ; n=19$ experiments), expressed as percentage of the average EPSP value preceding the pairing event, following short-interval pairings $(C 1)$ and long-interval pairings $(C 2)$. $C 3$ shows the average values obtained after division of each individual segment following short-interval pairing by that following the subsequent long-interval pairing. D1 and $D 2$, Same as $C 1$ and $C 3$, but with higher time resolution. D3, Same as D2, but using measurements of field EPSP amplitude.

average peak potentiation following a single conjunction event was $34 \pm 2.9 \%$ of the baseline level and a significant potentiation (mean, $9.3 \pm 2.4 \% ; P<0.05$ ) remained 60 min after the conjunction. No conjunction-induced potentiation $(0.2 \pm 1.6 \% ; n$ $=9$; measured $1-2$ min after the conjunction) was elicited when the test input had been saturated with respect to LTP by repeated homosynaptic tetanization, and the NMDA receptor antagonist APV (50 $\mu \mathrm{M}$ in the perfusion fluid or drop application, $5 \mathrm{mM}$ ) prevented the induction $(n=6)$, but did not affect once established conjunction-induced potentiation $(n=4)$. These results suggest an equivalence between the conjunction-induced potentiation and LTP.

As reported previously (Hanse et al., 1991; see also Fig. 3B, uppermost records), a prolonged potentiation (not seen in the slope measurements in Figs. $2 A, 3 A$ ) was also generally observed following the long test-conditioning intervals. In contrast to LTP, this potentiation was seen as a prolongation of the field EPSP rising phase with no change of the initial slope, and may represent a nonassociative potentiation distinct from LTP (Hess and Gustafsson, 1990; Hanse et al., 1991).

\section{Onset of LTP induced by single volley conjunction}

To establish the onset and early time course of LTP elicited by the conjunction, a sequence of a long- $(-300 \mathrm{msec})$, a short$(-5 \mathrm{msec})$, and a long- $(-300 \mathrm{msec})$ interval pairing event was performed with 15-20 min between each event (Fig. 3A). The first long-interval pairing was made in order to saturate for the nonassociative potentiation referred to above (cf. Hanse et al., 
1991) and the second one to control for other possible unspecific effects of the conditioning tetanus on the test EPSP. Figure 3, $C 1$ and $D 1$, shows, at different time scales, the average time course of LTP induced by conjunction $(n=19)$. As in the CAl region (Gustafsson et al., 1989), there appears to be a delay of a few seconds before LTP starts to develop $(D 1)$. It then grows for about $30 \mathrm{sec}$, and is thereafter rather well maintained throughout a $10 \mathrm{~min}$ recording period (Cl).

The long-interval pairing events often gave rise to a small heterosynaptic depression. As shown in Figure $3 C 2$, the depression appeared to start some $30-60 \mathrm{sec}$ after the pairing and largely decayed within 5-10 min. In an attempt to examine whether this depression is also evoked at the short-interval pairing, and thus affecting the potentiation time course, short- and long-interval pairings were also performed following homosynaptic tetanizations that had saturated LTP in the test input (see below), and following APV application. In both of these situations, no heterosynaptic depression was observed, neither after the long-interval pairing nor after the short-interval one (not illustrated). Thus, it cannot be decided whether this depression also occurred at the short-interval pairings together with LTP. Nevertheless, assuming that this depression is evoked by the short-interval pairing and that it represents a process that is independent of LTP, the LTP time course should be obtained by dividing the outcome of each short-interval pairing with the values given by the subsequent long-interval pairing. Figure 3, $C 3$ and $D 2$, shows that this procedure adds a slow growth phase to the potentiation during the second minute after pairing, and to an evident decay during the first 10 min period. A similar, but less noisy, potentiation time course was obtained using measurements of the EPSP amplitude rather than of the initial slope (Fig. 3D3).

\section{Onset of LTP induced by homosynaptic tetanization}

The time course of LTP following homosynaptic tetanization can be obtained by dividing the total potentiation following single brief tetani by the augmentation and posttetanic potentiation that follow such trains (Gustafsson et al., 1989). To block LTP induction, and thus obtain augmentation and posttetanic potentiation in isolation, tetani were first delivered in the presence of APV $(50 \mu \mathrm{M})$ (Fig. $4 A$ ). Figure $4 B 1$ shows that the potentiation resulting from a single 10 -impulse tetanus in the presence of APV consists largely of an initial fast component followed by a considerably smaller $(1-2 \%)$ potentiation that decayed within 3-6 min. The initial component was found to decay in an approximately exponential manner with a time constant of $10.6 \mathrm{sec}(n=10)$ and likely represents augmentation (Magleby and Zengel, 1976; McNaughton, 1982). When examined in the same slice $(n=2)$, augmentation increased with the number of impulses in the stimulus train, from a peak value of $4.9 \%$ (5 impulses) to $20.6 \%$ (10 impulses) and $44.6 \%$ (40 impulses) (see also Fig. 11, left column). In agreement with a previous study (McNaughton, 1980), the magnitude of augmentation was found to be considerably larger for synapses in the outer third than in the middle third of the molecular layer. The small, slower, potentiation component did not become larger when doubling the stimulus intensity during tetanization, that is, showed no signs for a cooperativity requirement for its induction (McNaughton et al., 1978), and thus represents posttetanic potentiation (McNaughton, 1982) rather than some partial activation of an NMDA-dependent potentiation process.

Following washout of APV, the single 10-impulse tetanus (at test intensity) gave rise to a potentiation that decayed within 10 min (Fig. $4 A$ ). Virtually identical potentiations could be evoked in succession, indicating no interaction between successive inductions. These transient potentiations were observed also when such tetani were applied before APV application and were thus not a consequence of the prior cxposure to APV. As will bc shown below, stronger stimulation in the same slices evoked more prolonged potentiation, demonstrating that these decaying potentiations were not a consequence of poor conditions of the slices. Figure $4 B 2-B 4$ shows the average potentiation $(n=10$ experiments) obtained after washout of APV before $(B 2)$ and after $(B 3, B 4)$ division by the potentiation obtained in APV (for details, see Fig. 4 caption). In agreement with conjunction-induced LTP, the tetanus-induced LTP shows a latency of a few seconds, and a rapid growth during some $30 \mathrm{sec}$. The potentiation thereafter starts to decay slowly already at about a minute after the tetanus. A similar behavior can also be observed in the less noisy graph obtained using amplitude measurements (Fig. 4B4).

\section{Occlusion between transient and sustained LTP}

The transient potentiation described above was, like LTP, dependent on NMDA receptor activation for its induction. Moreover, when using smaller test EPSPs, no potentiation (except augmentation and posttetanic potentiation) was observed following tetanization at test intensity (not illustrated), indicating a requirement for cooperativity (McNaughton et al., 1978) for the induction of this transient potentiation. To examine the relation between this transient, NMDA-dependent, potentiation and LTP (seen as a sustained potentiation), a 10-impulse test tetanus was given before and after saturation of LTP by repeated homosynaptic tetanization. As shown from one such experiment in Figure $5 A$, the test tetanus was delivered before (T1) and at three different times, $5 \mathrm{~min}$ (T2), $15 \mathrm{~min}$ (T3), and $60 \mathrm{~min}$ (T4), after the saturating tetanization. On average, the saturating tetanization produced a $169 \%$ increase of field EPSP initial slope $(127-228 \% ; n=6)$, which compares well to the range observed in the CAl region (120-200\%; Gustafsson et al., 1989). Figure $5 C$ shows that the test tetani, which prior to the saturating tetanization elicited on average $(n=6)$ a transient potentiation of $28 \%$ at peak (T1), evoked no potentiation at all within the first hour after saturating tetanization (T2-T4). It can be noted in Figure $5 A$ that stimulus intensity was lowered after saturation of LTP in order to obtain a potentiated field EPSP of the same magnitude as that before saturating tetanization. To ascertain that the induction should not be weaker after saturation of LTP than before, the field EPSP was not fully returned to the original level. Moreover, in three of the experiments the test tetanus was delivered a fifth time (T5) at $1.2 \times$ test intensity, this stronger tetanus also unsuccessful in eliciting any potentiation (Fig. $5 \mathrm{~A}$ ). Responses to the test tetani elicited before (T1, solid line) and $60 \mathrm{~min}$ after saturating tetanization (T4, broken line) are shown in Figure $5 B$ and do not indicate less postsynaptic activity during the latter tetanus. In view of this occlusion, the transient potentiation may represent the early part of the LTP process, and is therefore referred to as LTP.

\section{LTP time course following strong homosynaptic tetanization}

The amount of LTP induced by saturating tetanization indicates that a single 10 -impulse tetanus at test intensity evoked only about 10-20\% of maximal peak LTP capacity. By using higher stimulus intensity (twice test intensity) during the 10-impulse 

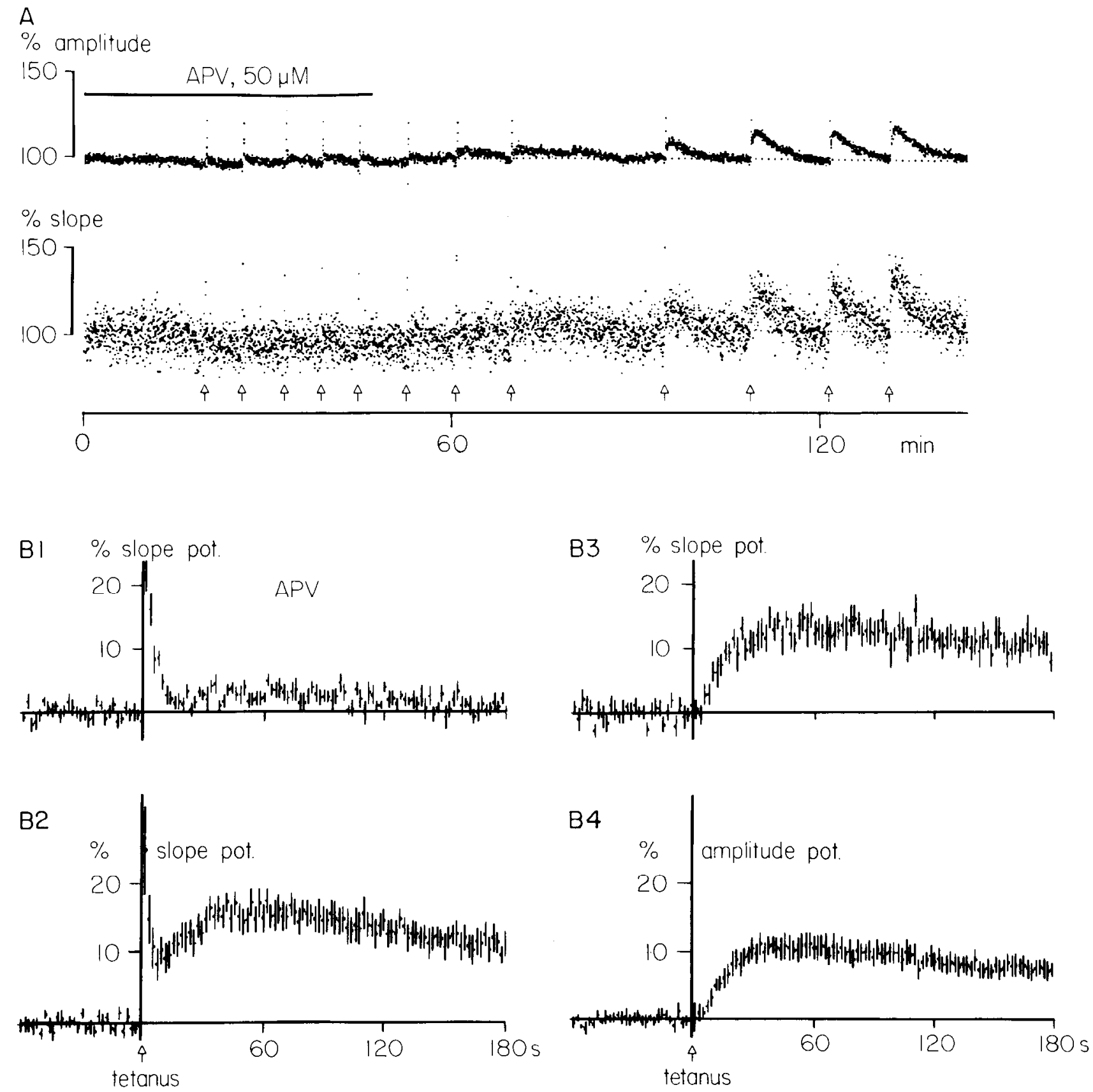

Figure 4. Early time course of LTP elicited by weak homosynaptic tetanization. $A$, Measurements of the initial slope and the amplitude of field EPSPs are shown from one experiment for a series of responses evoked at $0.5 \mathrm{~Hz}$. The values are plotted as percentages of baseline values. Tetani (10 impulses, $100 \mathrm{~Hz}$, test intensity) were delivered at times indicated by arrows. APV at $50 \mu \mathrm{M}$ was present in the perfusion fluid during the first part of the experiment and was subsequently washed out, as indicated. $B$, Average field EPSP slope changes $( \pm \mathrm{SEM} ; n=10$ experiments, three or four potentiations from each experiment), expressed as percentage of the average EPSP value obtained preceding the tetanus. $B 1$, Average potentiation obtained with $A P V$ present in the solution. $B 2$, Average potentiation obtained after $A P V$ washout. $B 3$, Same as in $B 2$, but after cach individual potentiation had been divided by the average potentiation obtained for that experiment in the presence of APV. B4, Same as $B 3$, but using measurements of field EPSP amplitude.

tetanus, considerably larger and sustained LTP was produced (Fig. 6A, compare $\mathrm{T} 1$ and $\mathrm{T} 2$ ). The EPSP increase at the peak of the potentiation following tetanization at twice test intensity varied between $47 \%$ and $140 \%$ (mean, $91 \pm 5 \% ; n=36$ ), implying that, on average, about $50 \%$ of maximal LTP capacity is evoked by this single brief train. The early time course of LTP elicited by such strong tetani was obtained from experiments ( $n$ -20 slices) in which the potentiation obtained following washout of APV was divided by that obtained in the presence of this drug for that input. Figure $6 B 3$ shows that also in this case LTP, after a latency of a few seconds, grows rapidly for about $30 \mathrm{sec}$. It thereafter displays a small, slow additional growth for about a minute, which is followed by a slow, continuous, but decelerating decay (Fig. 6A; see also Fig. 8). In seven experiments in which the potentiation was followed for $60 \mathrm{~min}, 35-69 \%$ (mean, $57 \pm 4 \%$ ) of the peak value remained at that time.

As judged from the changes observed following tetanization in the presence of APV (Fig. 6B2) or from the control input in 


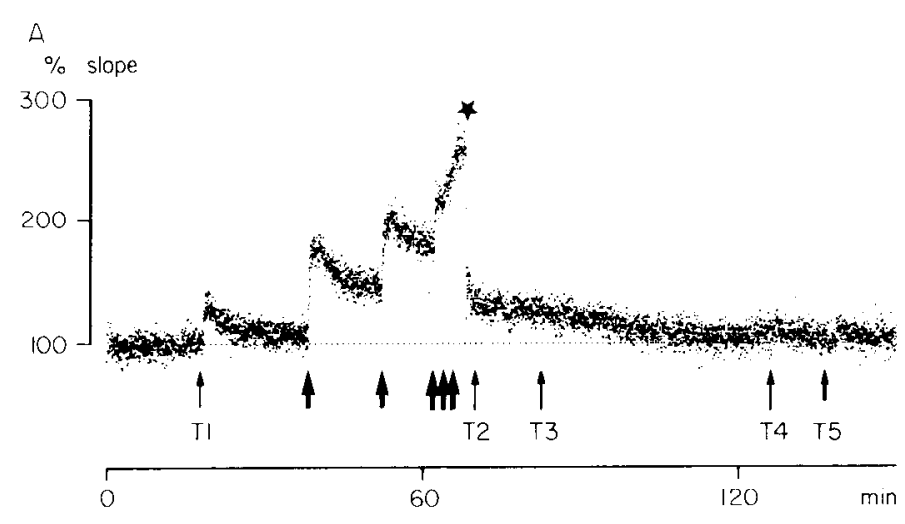

B

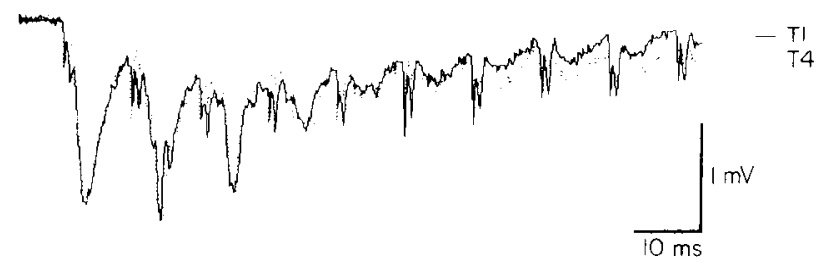

C
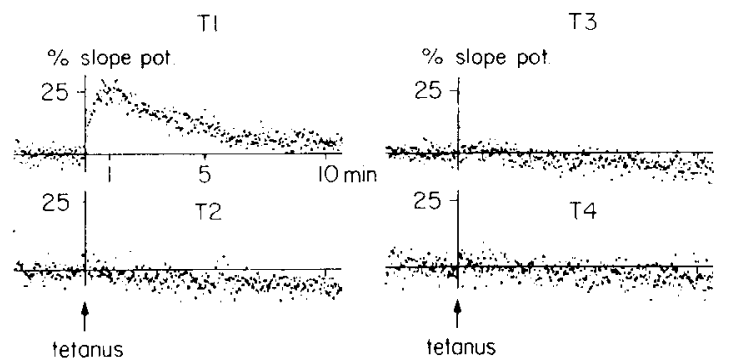

Figure 5. Persistent LTP occludes transient potentiation induced by weak homosynaptic tetanization. $A$, Measurements of the initial slope of field EPSPs are shown from one experiment for a series of responses evoked at $0.5 \mathrm{~Hz}$. The values are plotted as percentages of baseline values. Thin arrows indicate tetani (10 impulses, $100 \mathrm{~Hz})$ delivered at test intensity. Thick arrows indicate tetani (10 impulses, $100 \mathrm{~Hz})$ delivered at twice test intensity. The star indicates reduction in stimulus intensity. $T I$ was delivered prior to repeated, strong tetanization. $T 2-$ $T 4$ were delivered 5,15 , and $>60 \mathrm{~min}$ after the last strong tetanization, respectively. $T 5$ was delivered $>10 \mathrm{~min}$ after $T 4$ at 1.2 times test intensity. $B$, Response during the $T l$ tetanization (solid line), and the $T 4$ tetanization (broken line). $C$, Average field EPSP slope changes, expressed as percentage of the average baseline value, following tetani TI$T 4$. The results are taken from six experiments such as that illustrated in $A$.

the absence of APV (Fig. 6B4), these strong tetani did not give rise to any unspecific depression. To explore the possibility of a depression not revealed during blockade of NMDA receptor channels, or by the control input, the test tetanus (at twice test intensity) was also delivered after saturating tetanization (Fig. $7 A$ ). As shown in Figure $7 B$, when delivered 10 min after maximal LTP had been evoked (T2), the test tetanus produced on average ( $n=6$ experiments) only a very small transient potentiation giving no indication of a hidden depression. It can also be noted that there was little recovery of the potentiation evoked by the test tetanus more than 70 min after the saturating tetanization (T3). On average, the difference between the potentiation evoked at T2 and T3, that is, at 10 and $>70$ min after
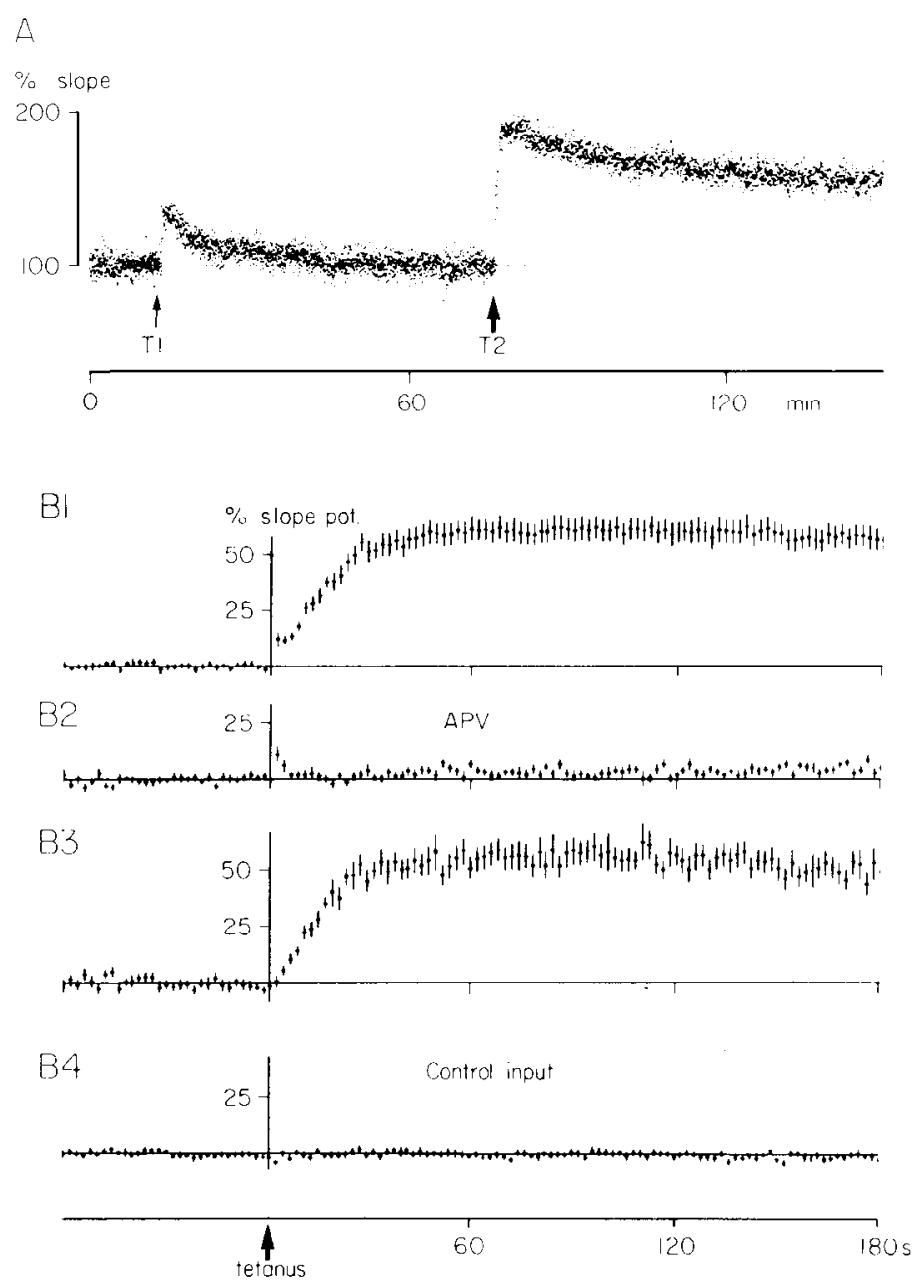

Figure 6. Early time course of LTP elicited by strong homosynaptic tetanization. $A$, Measurements of the initial slope of field EPSPs are shown for a series of responses evoked at $0.5 \mathrm{~Hz}$. The values are plotted as percentages of baseline values. $T l$ (thin arrow) indicates a tetanus (10 impulses, $100 \mathrm{~Hz}$ ) delivered at test intensity, and $T 2$ (thick arrow) indicates a tetanus $(10$ impulses, $100 \mathrm{~Hz}$ ) delivered at twice test intensity. $B$, Average field EPSP slope changes ( $\pm \mathrm{SEM} ; n=20$ experiments), expressed as percentage of the average EPSP value preceding the tetanus. $B 1$, Average potentiation obtained without APV in the perfusion fluid. $B 2$, Average potentiation obtained with APV present in the perfusion fluid. $B 3$, Same as in $B 2$, but after each individual potentiation had been divided by the average potentiation obtained for that experiment in the presence of APV. B4, Same as $B I$, but for the control input activated $1 \mathrm{sec}$ out of phase with respect to the test input.

saturating tetanization, was no more than the decay of the LTP during that period; that is, the strong (twice test intensity) tetanization merely returned LTP back to the saturated state.

\section{Influence of induction strength on LTP time course}

The potentiations following both test and twice test intensity tetanization did not display a stereotyped decay phase. In fact, there was a quite large variability. To demonstrate this variability, the potentiations following test intensity tetanization were subdivided into three groups: those that lasted less than $10 \mathrm{~min}$, lasted between $10-30 \mathrm{~min}$, and lasted more than 30 $\mathrm{min}$. The average potentiation for each group is plotted in Figure $8 A 1-A 3$. The potentiations following twice test intensity tetanization ( $n=12$ ) were divided into those that decayed the most and the least, respectively, and the resulting average potentiation 

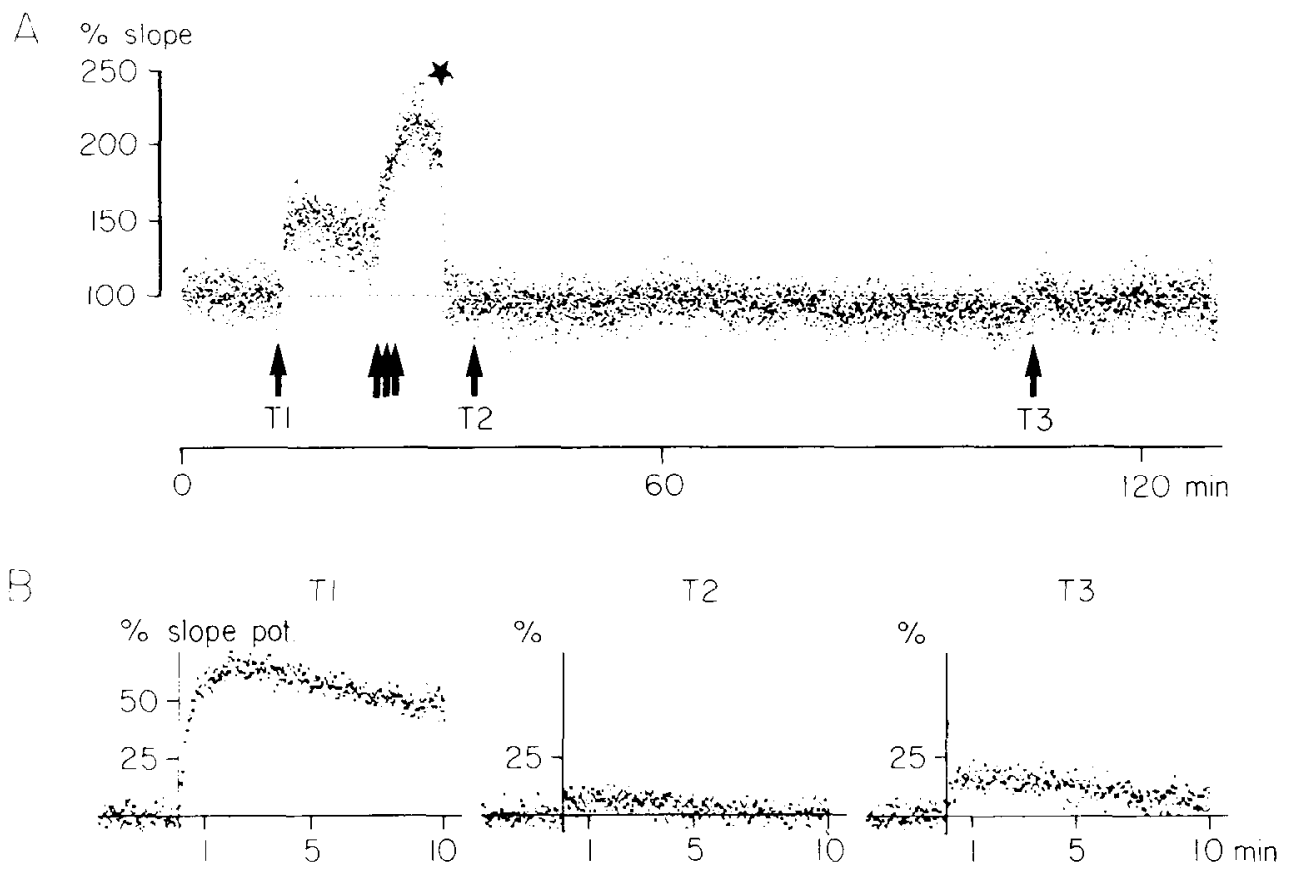

Figure 7. Effect of strong homosynaptic tetanization following saturation of LTP. $A$, Measurements of the initial slope of field EPSPs are shown from one experiment for a series of responses evoked at $0.5 \mathrm{~Hz}$. The values are plotted as percentages of the baseline valucs. Arrows indicate tetani $(10 \mathrm{im}$ pulses, $100 \mathrm{~Hz}$ ) delivered at twice test intensity. The star indicates reduction in stimulus intensity. $T l$ was delivered prior to repeated, strong tetanization. $T 2$ and $T 3$ were delivered 10 and $>70$ min after the last strong tetanization, respectively. $B$, Average field EPSP slope changes, expressed as percentage of baseline values, following tetani $T l-$ $T 3$. The average results in $B$ are taken from six experiments such as that illustrated in $A$. for these two groups is plotted in $A 4$ and $A 5$. For the potentiations following test intensity tetanization $(A 1-A 3)$, there was some correlation between magnitude and duration of the potentiation, the average peak potentiation increasing from $17.2 \%$ $(n=30)$ to $29.0 \%(n=10)$ and to $37.4 \%(n=7)$ when moving from the least stable $(A I)$ to the most stable ones $\left(A_{3}\right)$. In some experiments, the tetanization at test intensity (T1) was followed by a somewhat stronger tetanus ( $1.2 \times$ test intensity, T2), leading to a larger and more sustained LTP (Fig. $8 B$ ). On average ( $n=$ 5), this $20 \%$ increase in stimulation intensity enhanced the peak potentiation from $21.8 \pm 0.9 \%$ to $36.4 \pm 3.9 \%(P<0.05)$, and the fraction of the peak potentiation that remained after $10 \mathrm{~min}$, from $0.18 \pm 0.07$ to $0.36 \pm 0.09(P<0.05)$. This result indicates that the observed variability in LTP magnitude and stability obtained with tetanization at test intensity (illustrated in Fig. $8 A 1-A 3)$ is caused by variation in the induction strength given by such tetani in the different slices.

An additional point of interest is when and how these various potentiations diverge from each other. To illustrate this, the potentiations shown in Figure $8 A$ were normalized with respect to the late part of their rising phases (note that these curves also include augmentation and posttetanic potentiation) and plotted superimposed in Figure $8 C$. This shows that the two groups of transient potentiations $(A I$ and $A 2)$ diverge from each other already within the first 1-2 min after tetanization, and decay with clearly different rates. The more stable potentiations ( $A 3-$ $A 5)$ also separate at about this time, with the potentiations evoked at twice test intensity ( $A 4$ and $A 5$ ) even displaying a continued growth for some additional $2 \mathrm{~min}$.

Figure $8 C$ indicates that most of the decay during the first half hour, for all groups of potentiation, takes place within the first 10 min after tetanization. However, even when evoked by tetani of twice test intensity, the potentiations continued to decay, albeit at a slower rate, during the first half hour. This slow decay is indicated in Figure 9 for 12 potentiations that were followed for an hour. In this figure, the fractions of peak LTP remaining $30 \mathrm{~min}(A)$ and $60 \mathrm{~min}(B)$ after tetanization are plotted against that remaining after $10 \mathrm{~min}$. These plots first demonstrate that the amount of decay observed during the first $10 \mathrm{~min}$ is a good indicator of that taking place within the first hour. They also show that the decay from 10 min and onward manifests itself as a near parallel displacement from the relation that indicates equality between the fractions of remaining I.TP. Taken at face value, such a parallel displacement suggests that there is a certain threshold, with respect to the fraction remaining after $10 \mathrm{~min}$, for more sustained potentiation, and that an increase of this fraction will lead to a progressively smaller decay from 10 min onward. The existence of such a threshold at fractions (10 $\mathrm{min}$ ) less than about 0.3 (Fig. 9) is further indicated by the fact that most of the potentiations with durations between 10-30 min (Fig. 8A2) had decayed to between $20 \%$ and $30 \%$ of peak value within $10 \mathrm{~min}$.

\section{Influence of stimulation parameters on LTP time course}

The above results indicate that stimulus intensity during the induction event influences the stability (and magnitude), but not the growth phase, of LTP in the dentate gyrus. Other parameters that may influence the time course include test stimulation frequency, test EPSP size, train frequency, train duration, and repetition of trains.

Test frequency. To examine whether the relatively high test frequency used for each input $(0.5 \mathrm{~Hz})$ could have been responsible for the pronounced decay of the LTP observed (cf. Staubli and Lynch, 1990), the potentiation evoked by single 10impulse tetani at test intensity was examined using two different test rates $(0.5 \mathrm{~Hz}$ and $0.05 \mathrm{~Hz})$. Since such tetani generally produce transient LTP, the same input was tested, first at the higher rate and then at the lower one. The change to the lower rate resulted in an increase of the field EPSP of $27 \pm 4.3 \%(n$ $=7$ ) (cf. Teyler and Alger, 1976), and stimulus intensity was adjusted to compensate for this increase. On average, the peak LTP was somewhat larger $(36.9 \pm 4.1 \%)$ at the low rate than at the faster one $(30.1 \pm 3.1 \% ; P>0.05 ; n=7)$. Despite this, the fraction of peak LTP remaining after $10 \mathrm{~min}$ was lower at 


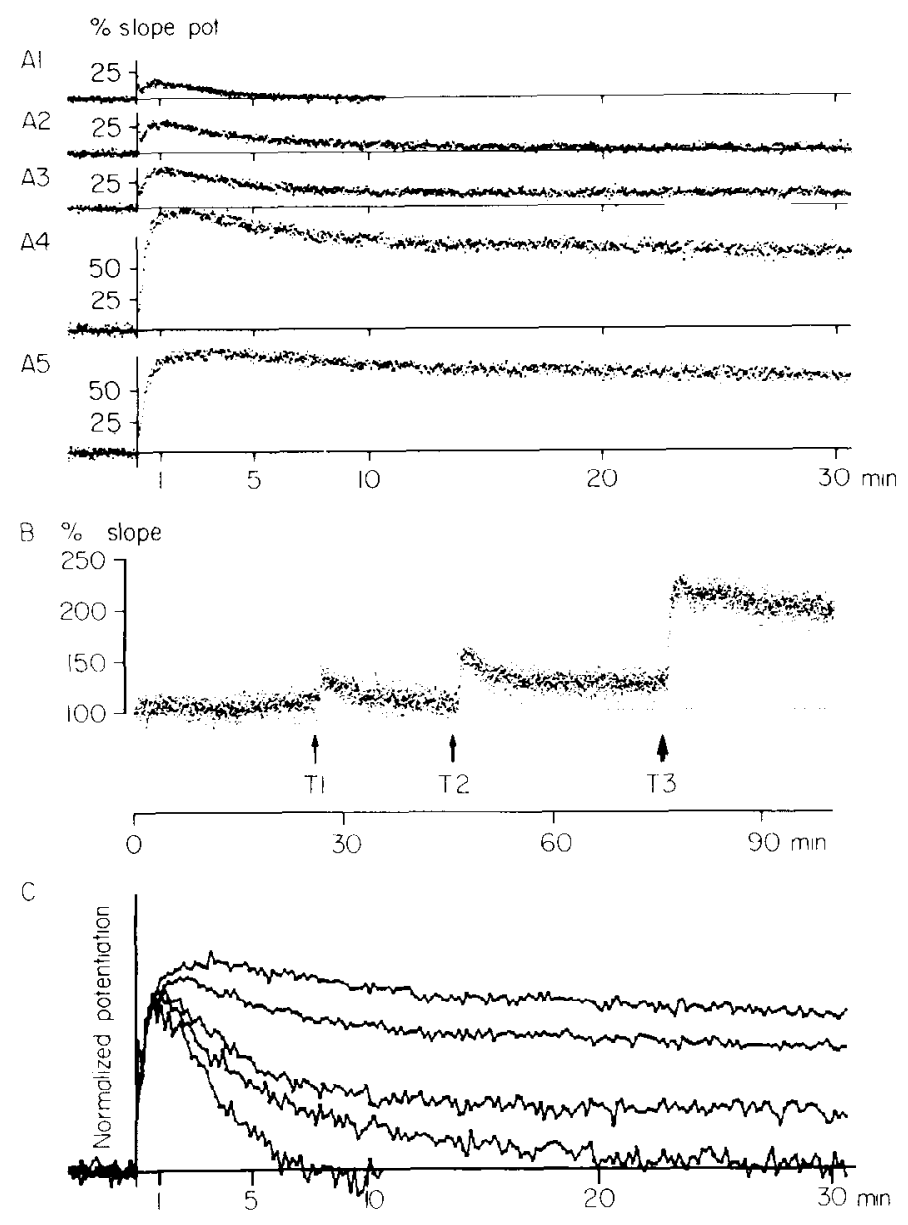

Figure 8. Comparison between time courses of LTPs with different duration and magnitude. $A$, Average potentiation of field EPSP slope following 10 -impulse $(100 \mathrm{~Hz})$ tetani. $A 1$, Potentiations with durations less than $10 \mathrm{~min}$ (tetani at test intensity, $n=30$ ). $A 2$, Potentiations with durations between 10 and $30 \mathrm{~min}$ (tetani at test intensity, $n=10$ ). $A 3$, Potentiations with durations longer than $30 \mathrm{~min}$ (tetani at test intensity, $n=7) . A 4$ and 45 , Potentiations following tetanus at twice test intensity divided into those that decayed most $(A 4 ; n=6)$ and those that decayed least $(A 5 ; n=6)$ during the first $10 \mathrm{~min} . B$, Measurements of the initial slope of the field EPSPs are slown from one experiment for a series of responses evoked at $0.5 \mathrm{~Hz}$. The values are plotted as percentages of baseline values. Arrows indicate tetani $(10 \mathrm{impulses}, 100 \mathrm{~Hz})$ delivered at test intensity $(T l), 1.2 \times$ test intensity $(T 2)$, and $2 \times$ test intensity (T3). $C$, Average potentiations shown in $A$ plotted together after scaling to a common magnitude $40 \mathrm{sec}$ after tetanization. To reduce scatter, each point is an average of five consecutive values.

the low rate, but not significantly so $(0.10 \pm 0.08$ vs $0.20 \pm$ $0.06 ; n=7$ ), indicating no tendency for a more stable potentiation at lower test frequencies. The LTP following tetanization (10 impulses) at twice test intensity was also monitored with a test frequency of $0.05 \mathrm{~Hz}$. This LTP reached on average $(n=$ 4) a peak potentiation of $83 \pm 14 \%$, and a fraction of $0.71 \pm$ 0.14 of the peak potentiation remained $10 \mathrm{~min}$ after the tetanization. These values were not significantly different from those obtained for the potentiation monitored with $0.5 \mathrm{~Hz}(93 \pm 5 \%$ and $0.74 \pm 0.02$, respectively; $n=36$ ).

Test EPSP magnitude. Synapses activated during the tetanus may not all be subjected to the same induction conditions. In five experiments, the stimulus intensity to one of the stimulating electrodes was alternated between two levels, one producing "ordinary" test EPSPs and the other small EPSPs that varied
Table 1. LTP measured with small- and ordinary-sized test EPSPs following tetanization at ordinary $(1 \times)$ test intensity and at twice ordinary $(2 \times)$ test intensity

\begin{tabular}{|c|c|c|c|}
\hline & $\begin{array}{l}\text { Peak LTP } \\
(\% \pm \text { SEM })\end{array}$ & $\begin{array}{l}\text { Fraction of peak } \\
\text { LTP after } 10 \mathrm{~min} \\
( \pm \text { SEM })\end{array}$ & $n$ \\
\hline \multicolumn{4}{|l|}{$1 \times$ test intensity } \\
\hline Small EPSP & $17.1 \pm 1.9$ & $0.13 \pm 0.12$ & 5 \\
\hline Ordinary EPSP & $18.6 \pm 3.4$ & $0.13 \pm 0.19$ & 5 \\
\hline$p$ & $>0.05$ & $>0.05$ & \\
\hline \multicolumn{4}{|l|}{$2 \times$ test intensity } \\
\hline Small EPSP & $77.1 \pm 18.0$ & $0.47 \pm 0.10$ & 5 \\
\hline Ordinary EPSP & $67.4 \pm 17.1$ & $0.57 \pm 0.06$ & 5 \\
\hline$p$ & $>0.05$ & $>0.05$ & \\
\hline
\end{tabular}

from $12 \%$ to $62 \%$ of the ordinary test EPSP size. These small EPSPs would then be mediated by the afferents most easily activated by the stimulating electrode, and the associated synapses may be situated in the center of the activated dendritic region. Both EPSPs were subsequently used for estimation of the potentiation produced by tetanization. The input was twice tetanized by a single 10-impulse train, first at ordinary test intensity producing a transient LTP, and subsequently at twice ordinary test intensity producing a more stable one. In neither case was there any statistically significant difference in LTP time course and magnitude when estimated using the small EPSPS compared with using the large ones (Table 1), demonstrating that the observed time course is not a function of the test EPSP size.

Tetanization frequency. Ten-impulse trains at frequencies of $20,50,100$, and $400 \mathrm{~Hz}$ were delivered, each in a different slice, at both test and twice test intensity. Figure 10 shows that, on average, trains at $20 \mathrm{~Hz}(n=12)$, independently of stimulus intensity, were essentially ineffective in producing potentiation (or depression; cf. Bramham and Srebro, 1987). Using test intensity only the $100 \mathrm{~Hz}(n=47)$ and $400 \mathrm{~Hz}(n=10)$ tetani evoked any appreciable LTP, and there was no statistically significant difference in the early decay of the LTPs evoked by these tetani: $0.16 \pm 0.03(100 \mathrm{~Hz})$ and $0.27 \pm 0.10(400 \mathrm{~Hz})$ of peak LTP remaining $10 \mathrm{~min}$ after the induction. In five experiments, trains (10 impulses, test intensity) at $100 \mathrm{~Hz}$ and at $400 \mathrm{~Hz}$ were delivered in succession to the same input. Both tetanizations gave rise to a transient potentiation, and paired analysis did not reveal any significant difference in peak potentiation or in fraction of peak potentiation remaining after 10 $\min$. At twice test intensity, a notable feature was that $100 \mathrm{~Hz}$ ( $n=36$ ) trains were significantly more efficient in producing large and stable LTP than $400 \mathrm{~Hz}(n=9)$ and $50 \mathrm{~Hz}(n=7)$ trains, the average peak potentiation being $93.4 \pm 4.9 \%, 64.2$ $\pm 6.0 \%$, and $36.6 \pm 4.9 \%$ for the 100,400 , and $50 \mathrm{~Hz}$ trains, respectively, and the fraction of peak potentiation remaining after $10 \mathrm{~min}$ being $0.74 \pm 0.02,0.58 \pm 0.05$, and $0.48 \pm 0.08$.

Previous studies in the dentate gyrus have indicated that repetitive burst stimulation is an efficient means to evoke stable LTP (Greenstein et al., 1988). In the present experiments, five four-impulse, $100 \mathrm{~Hz}$ trains at $5 \mathrm{~Hz}$ were given at test intensity, and the resulting potentiation was compared to that given in the same input by an equal number (20) of impulses at $100 \mathrm{~Hz}$ (at test intensity) $(n=7)$. In both cases, a small decaying LTP 
A

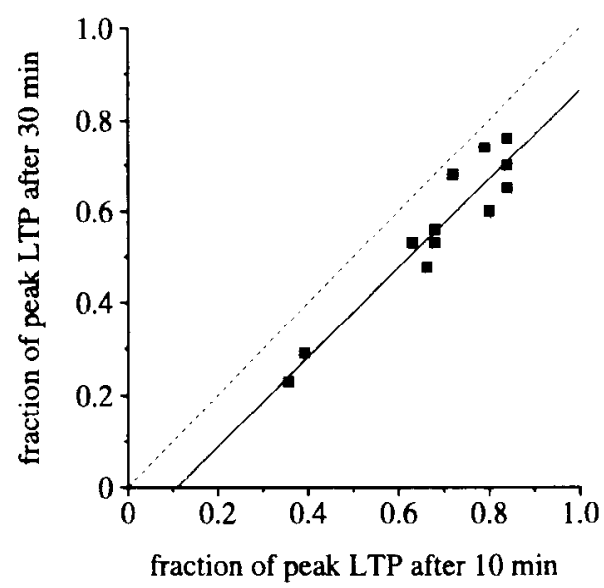

B

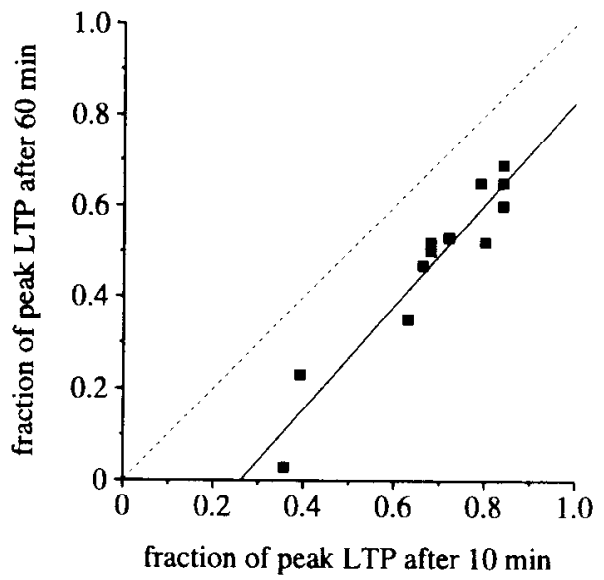

Figure 9. Relation between amounts of LTP at different times after the induction, expressed as fraction of peak LTP. Values are taken from the potentiations included in Figure $8 A 2-A 5$ that were followed for at least $60 \mathrm{~min}$. Broken lines represent equality between the fractions. Solid lines are linear regression lines. $A$, Fraction of peak LTP remaining after $10 \mathrm{~min}$ versus fraction of peak LTP remaining after $30 \mathrm{~min}(r=$ $0.95 \pm 0.10 ; n=12)$. $B$, Fraction of peak LTP remaining after $10 \mathrm{~min}$ versus fraction of peak LTP remaining after $60 \min (r=0.95 \pm 0.09 ; n=12)$. was observed. In fact, the peak LTP and the fraction of peak LTP remaining after $10 \mathrm{~min}$ were on average smaller following burst stimulation $(13.3 \pm 2.6 \% ; 0.06 \pm 0.09)$ than following the single train $(30.1 \pm 4.0 \% ; 0.27 \pm 0.05)$.

Experiments in vivo have demonstrated that LTP is more stable when evoked by a larger number of trains (Linden et al., 1987). Thus, while two brief trains produce an LTP that fully decays within 1-2 hr, eight such trains produce a LTP stable over hours. In the present study, a 10-impulse tetanus at test intensity was given, first alone, and then repeated 10 timcs at a rate of $0.1-0.5 \mathrm{~Hz}$ ( $n=8$ experiments). The repetition of tetani led to a more stable LTP, as judged from the fraction of peak LTP remaining $10 \mathrm{~min}$ after the induction $(0.62 \pm 0.07$ vs 0.19 $\pm 0.04 ; P<0.001)$, and to a larger peak LTP $(68.3 \pm 3.2 \%$ vs $16.1 \pm 3.6 \% ; P<0.001)$. Inspection of postsynaptic responses during trains revealed a considerable larger postsynaptic activity for later trains, making it difficult to separate effects of repetition per se from increased induction strength for the later tetani.

Tetanus duration. Single $100 \mathrm{~Hz}$ trains consisting of $2,5,10$, and 40 impulses, respectively, were delivered at test and twice test intensity, each train in a different slice. Figure 11 shows that at test intensity (left column) all trains gave a largely tran- sient LTP, the potentiation following a 40-impulse train being on average $(n=19)$ neither much larger nor more prolonged than that following a 5 -impulse $(n=12)$ or a 10 -impulse train $(n=47)$ (Table 2$)$. At twice test intensity (right column) the 5 $(n=39), 10-(n=36)$, and 40-impulse $(n=6)$ trains all gave a large peak LTP averaging around $90 \%$ and a similarly large fraction of the peak value (about 0.75 ) remained at 10 min after tetanization (Iable 2). It can be noted that, at the higher tetanization intensity, even a two-impulse train $(n=6)$ produced a substantial potentiation of which a fraction of about 0.4 remained $10 \mathrm{~min}$ after the tetanus, that is, a potentiation that, although significantly less stable than those evoked by the longer trains at twice test intensity, was more stable than those evoked by the much longer tetani at test intensity.

\section{Role of postsynaptic activity and NMDA receptor activation during the induction event}

Results presented above suggest that stimulus intensity during the induction event is a critical parameter in determining the stabilization of LTP. To evaluate to what extent this effect of stimulus intensity is mediated via the amount of postsynaptic depolarization and resulting increase in NMDA receptor acti-
TEST INTENSITY
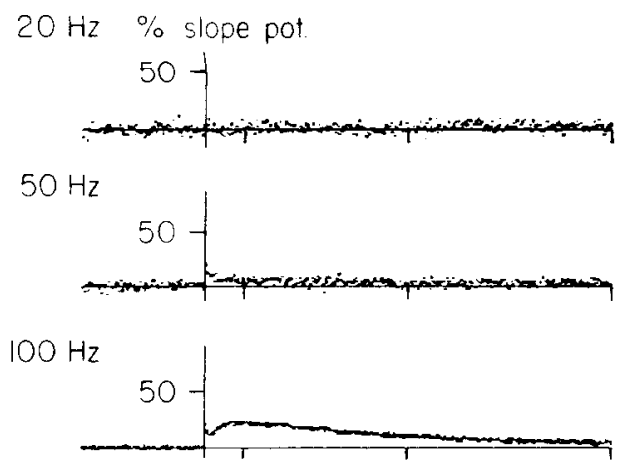

$400 \mathrm{~Hz}$

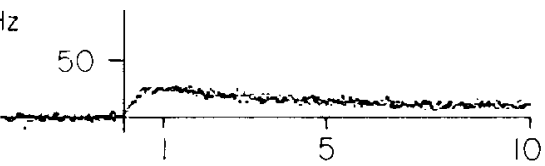

TWICE TEST INTENSITY
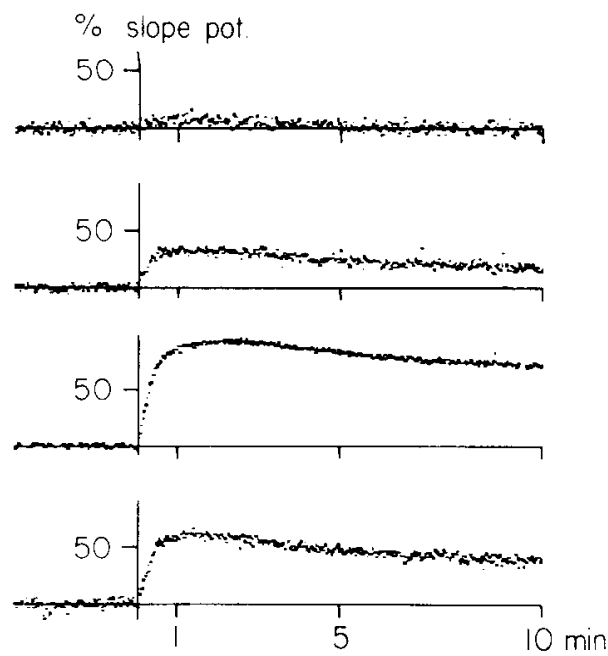

Figure 10. Time course of LTP following tetanization at various frequencies. All graphs show average field EPSP slope changes, expressed as percentage of the average value preceding the tetanus. The left column shows time courses following tetanization $(10 \mathrm{im}$ pulses) at test intensity using $20 \mathrm{~Hz}(n$ $=6), 50 \mathrm{~Hz}(n=5), 100 \mathrm{~Hz}(n=47)$, and $400 \mathrm{~Hz}(n=10)$ as tetanization frequency. The right column shows time courses following tetanization (10 impulses) at twice test intensity using 20 $\mathrm{Hz}(n=6), 50 \mathrm{~Hz}(n=7), 100 \mathrm{~Hz}(n$ $=36)$, and $400 \mathrm{~Hz}(n=9)$ as tetanization frequency. 
Figure 11. Time course of LTP following tetanization at various durations. All graphs show average field EPSP slope changes, in percentage of the average baseline value preceding the tetanus. The left column shows time courses following tetanization $(100 \mathrm{~Hz})$ at test intensity using 2 impulses ( $n=$ $10), 5$ impulses $(n=12), 10$ impulses $(n=47)$, and 40 impulses $(n=19)$ in the stimulus train. The right column shows time courses following tetanization $(100 \mathrm{~Hz})$ at twice test intensity using 2 impulses $(n=6), 5$ impulses ( $n$ $=39$ ), 10 impulses $(n=36)$, and 40 impulses $(n=6)$ in the stimulus train.

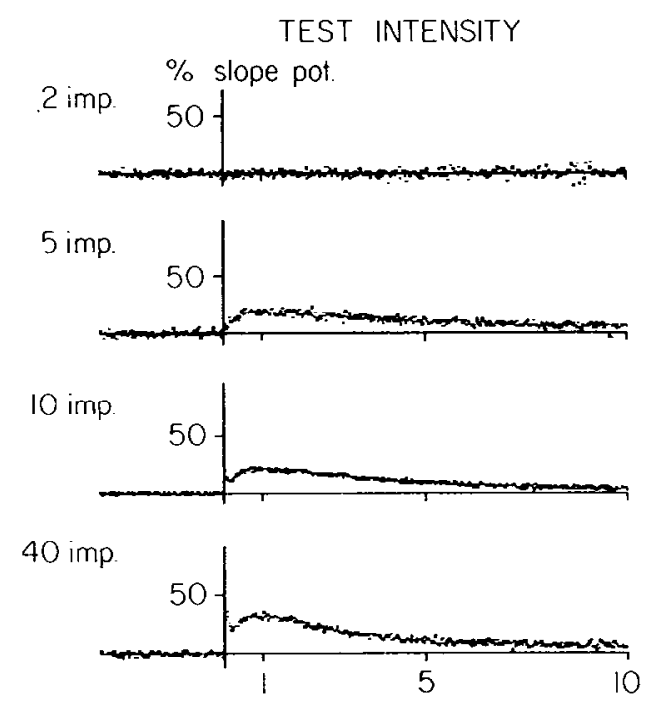

TWICE TEST INTENSITY
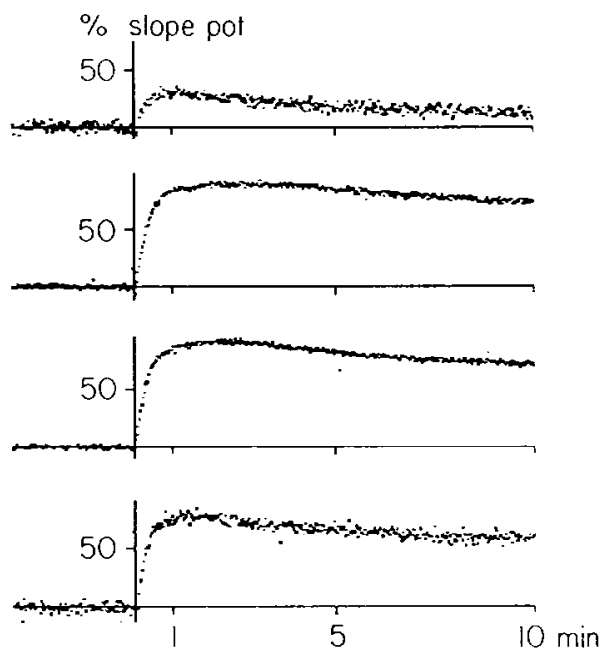

vation during the tetanization, the experiments described below were performed.

Temporal pairing of tetani. In a first set of experiments $(n=$ 6), tetani at test intensity were delivered to two different, but converging inputs. Figure $12 A$ shows from one of these experiments the typical result. While the separate activation of the inputs produced a largely transient potentiation in each input, a simultaneous delivery of the two trains (resulting in more postsynaptic activity for the same number of activated afferents) produced a larger and more sustained potentiation (Table 3). Note that the trains given separately were appreciably longer (40-impulse) than those given simultaneously (5-impulse).

Postsynaptic inhibition. In a second set of experiments $(n=$ 4) the input was tetanized (a single 10-impulse train at twice test intensity) at various intervals after the introduction of picrotoxin to the perfusion fluid. Figure $12 \mathrm{Bl}$ shows that the potentiation evoked by the tetanus changes from practically none at the time of onset of picrotoxin application (T1), to a small transient one (T2), and to a large sustained one (T3) as the concentration of the drug rises in the chamber (Table 3). The dendritic responses during the tetanus obtained at T2 and T3 are shown superimposed in $B 2$, demonstrating a greater amount of postsynaptic activity at the later tetanus (broken curve).

\begin{tabular}{|c|c|c|c|}
\hline $\begin{array}{l}\text { Number } \\
\text { of } \\
\text { impulses }\end{array}$ & $\begin{array}{l}\text { Peak LTP } \\
(\% \pm \text { SEM) }\end{array}$ & $\begin{array}{l}\text { Fraction of peak } \\
\text { LTP after } 10 \mathrm{~min} \\
( \pm \text { SEM })\end{array}$ & $n$ \\
\hline \multicolumn{4}{|c|}{$1 \times$ test intensity } \\
\hline 2 & - & - & 10 \\
\hline 5 & $21.5 \pm 2.1$ & $0.27 \pm 0.04$ & 12 \\
\hline 10 & $24.7 \pm 1.4$ & $0.16 \pm 0.03$ & 47 \\
\hline 40 & $33.7 \pm 2.6$ & $0.16 \pm 0.04$ & 19 \\
\hline \multicolumn{4}{|c|}{$2 \times$ test intensity } \\
\hline 2 & $32.1 \pm 3.4$ & $0.38 \pm 0.08$ & 6 \\
\hline 5 & $94.0 \pm 4.6$ & $0.78 \pm 0.01$ & 39 \\
\hline 10 & $93.4 \pm 4.9$ & $0.74 \pm 0.02$ & 36 \\
\hline 40 & $82.6 \pm 11.2$ & $0.70 \pm 0.02$ & 7 \\
\hline
\end{tabular}

NMDA receptor activation. According to present concepts regarding mechanisms involved in LTP induction, postsynaptic depolarization may act via its opening of NMDA receptor channels and associated calcium influx into the spine (Wigström and Gustafsson, 1985a; Malenka et al., 1989). Partial blockade of NMDA receptor activation would then produce a similar result as that with partial blockade of inhibition. Figure $12 \mathrm{C}$ shows that this is the case. During washout of APV, the potentiation produced by a 40 -impulse train at twice test intensity changed from a small transient one ( $\mathrm{T} 1$ and $\mathrm{T} 2$ ) via a larger but still substantially decaying one (T3), to a large, more sustained one (T4) (Table 3).

\section{Discussion}

The present results demonstrate that LTP in the dentate gyrus does not start to manifest itself until a few seconds after the induction event, and that it thereafter grows approximately linearly for about $30 \mathrm{sec}$. This growth phase was, in a qualitative sense, independent of the induction strength and the amount of LTP produced. These findings correspond well to previous findings for LTP in the CAl region (Gustafsson et al., 1989). In

Table 3. Peak LTP and fraction of peak LTP remaining $10 \mathrm{~min}$ after tetanus, at various degrees of postsynaptic depolarization and NMDA receptor activation during the induction

\begin{tabular}{|c|c|c|c|}
\hline Tetanus & $\begin{array}{l}\text { Peak LTP } \\
(\% \pm \text { SEM })\end{array}$ & $\begin{array}{l}\text { Fraction of } \\
\text { peak LTP } \\
\text { after } 10 \mathrm{~min} \\
( \pm \text { SEM })\end{array}$ & $n$ \\
\hline Single (T1) & $23.6 \pm 4.5$ & $0.18 \pm 0.06$ & 6 \\
\hline \multicolumn{4}{|l|}{ Single paired with } \\
\hline conditioning (T3) & $50.4 \pm 6.0$ & $0.56 \pm 0.07$ & 6 \\
\hline$p$ & $<0.001$ & $<0.001$ & \\
\hline At low picrotoxin (T2) & $33.8 \pm 2.0$ & $0.31 \pm 0.01$ & 4 \\
\hline At high picrotoxin (T3) & $85.0 \pm 13.7$ & $0.59 \pm 0.08$ & 4 \\
\hline$p$ & $<0.05$ & $<0.05$ & \\
\hline At high APV (T3) & $22.5 \pm 3.3$ & $0.11 \pm 0.07$ & 8 \\
\hline At low APV (T4) & $54.4 \pm 5.8$ & $0.62 \pm 0.06$ & 8 \\
\hline$p$ & $<0.001$ & $<0.001$ & \\
\hline
\end{tabular}

See Figure 12 for explanation of T1-T4. 

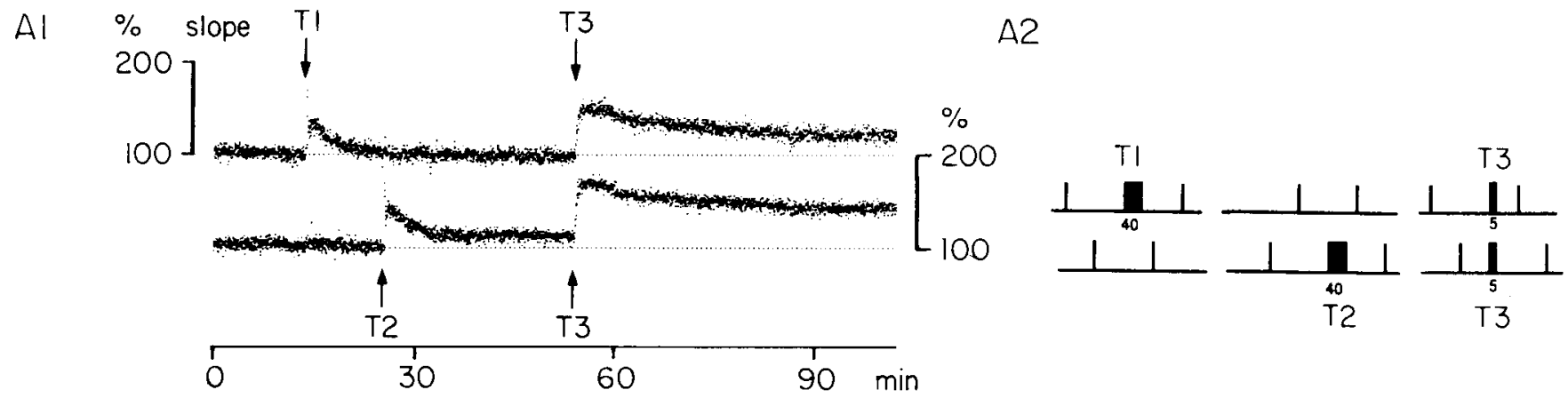

BI

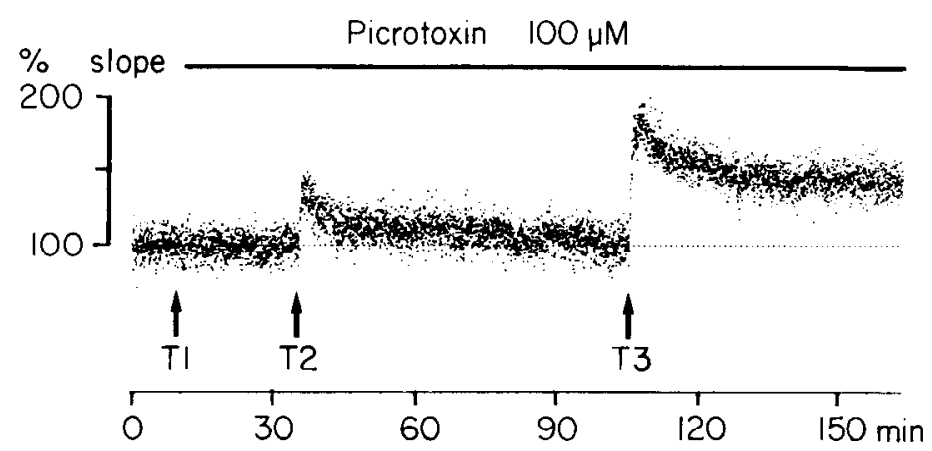

B2

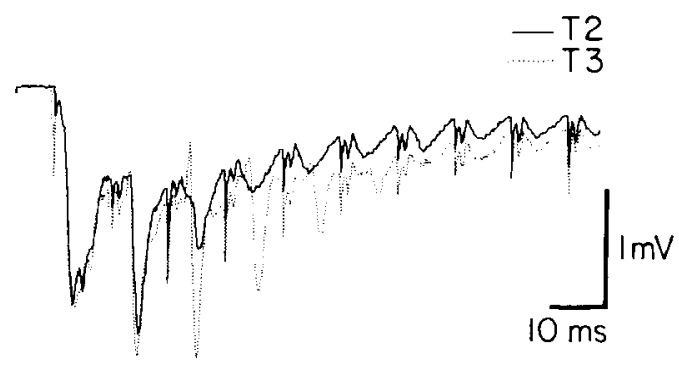

$\mathrm{Cl}$
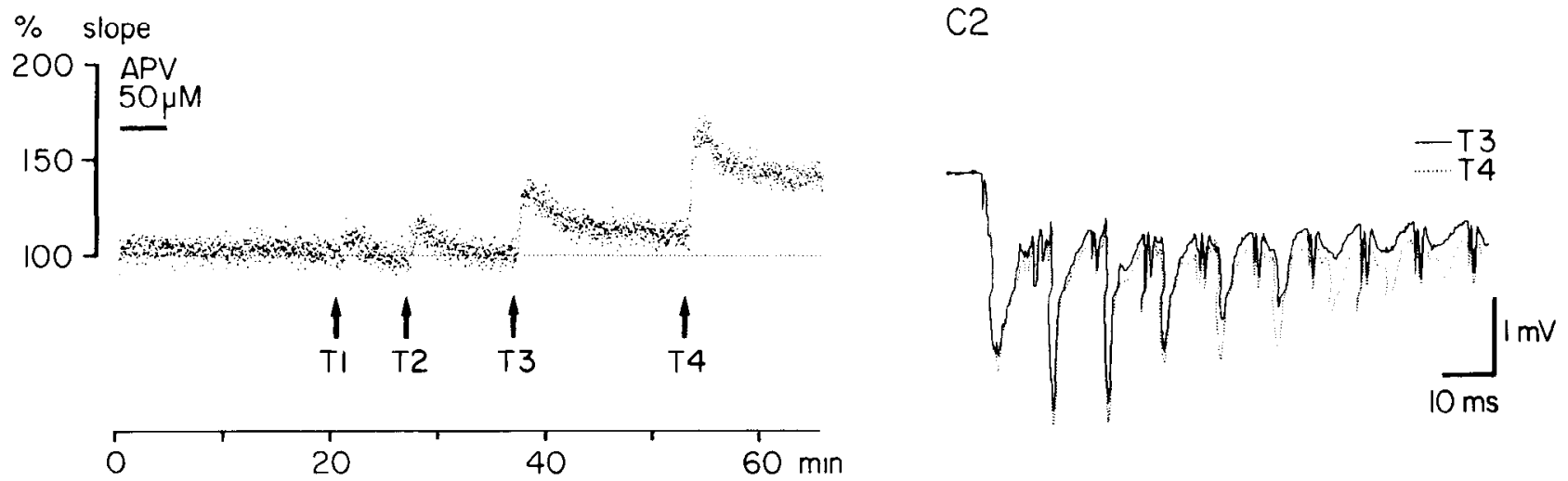

Figure 12. Increased postsynaptic activity, and increased NMDA receptor activation during the induction, improves the stability of LTP. $A 1$, Measurements of the initial slope of the field EPSPs are shown from one experiment for a series of responses evoked at $0.5 \mathrm{~Hz}$ to two independent inputs. The values are plotted as percentages of the average baseline value for each input. $T 1$ (arrow) indicates a tetanus (40 impulses, $100 \mathrm{~Hz}$ ) delivered at test intensity to the first input, and $T 2$ (arrow) indicates a tetanus ( 40 impulses, $100 \mathrm{~Hz}$ ) delivered at test intensity to the sccond input. $T 3$ (arrows) indicates simultaneous tetanization $(5$ impulses, $100 \mathrm{~Hz}$ ) to both inputs. A schematic representation of the stimulations of the two inputs are given in $A 2 . B 1$, Measurements of the initial slope of the field EPSPs are shown from one experiment for a series of responses evoked at $0.5 \mathrm{~Hz}$. Tetanizations (10 impulses, $100 \mathrm{~Hz}$, twice test intensity) were delivered at times indicated by arrows (TI-T3). Immediately following $T 1,100 \mu \mathrm{M}$ picrotoxin was added to the perfusion fluid. B2, Response during tetanization $T 2$ (solid line) and tetanization $T 3$ (broken line). C1, Measurements of the initial slope of the field EPSPs are shown from one experiment for a series of responses evoked at $0.5 \mathrm{~Hz}$. Tetanizations (40 impulses, $100 \mathrm{~Hz}$, twice test intensity) were delivered at times indicated by arrows (T1-T4). Washout of $50 \mu \mathrm{M}$ APV started at the beginning of the experiment as indicated. C2, Response during tetanization T3 (solid line) and tetanization T4 (broken line).

fact, when superimposing the early part of the LTPs from these two regions, there is a good agreement during the first $20 \mathrm{sec}$ after the tetanus (Fig. 13). This result may then indicate that the calcium influx triggers the same biochemical processes resulting in mechanistically identical modifications during this growing phase of LTP. Alternatively, this agreement in the early time course may reflect similar calcium kinetics in the postsynaptic spines in the two regions (cf. Gustafsson et al., 1989).

\section{Relation between early transient potentiation and LTP}

As in the CA1 region, LTP in the dentate gyrus could decay appreciably during the first $10-30 \mathrm{~min}$ after tetanization, and at weak tetanization intensity the potentiation decayed completely within 5-30 min. In CAl such an early decaying phase has been referred to as slowly decaying potentiation or shortterm potentiation and has been considered to be mechanistically separate from the sustained phase of LTP (Anwyl et al., 1989; Kennedy, 1989; see also Davies et al., 1989). This notion of a separation in expression mechanisms seems mainly based on the result that the transient potentiation elicited by NMDA application is not occluded by LTP (Kauer et al., 1988). However, the NMDA-induced potentiation may not be identical to tetanization-induced potentiation (Asztely et al., 1991). Moreover, in the CAl region the early decaying phase is largely oc- 
Figure 13. Comparison between the growth phase of LTP in the dentate gyrus and in the CAl region. A, Open circles represent average early time course of LTP in the CAI region following 10 impulse tetani ( $50 \mathrm{~Hz}$, test intensity), taken from Gustafsson et al. (1989). Solid squares represent average early time course of LTP in the dentate gyrus following 10 impulse tetani $(100 \mathrm{~Hz})$ at test intensity, same as Figure $4 B 4$. The curves were normalized with respect to their rising phases. $B$, Open circles, same as in $A$. Solid squares represent average early time course of LTP in the dentate gyrus following 10 impulse tetani (100 $\mathrm{Hz})$ at twice test intensity, same as Figure $6 B 3$. The curves were normalized with respect to their rising phases.
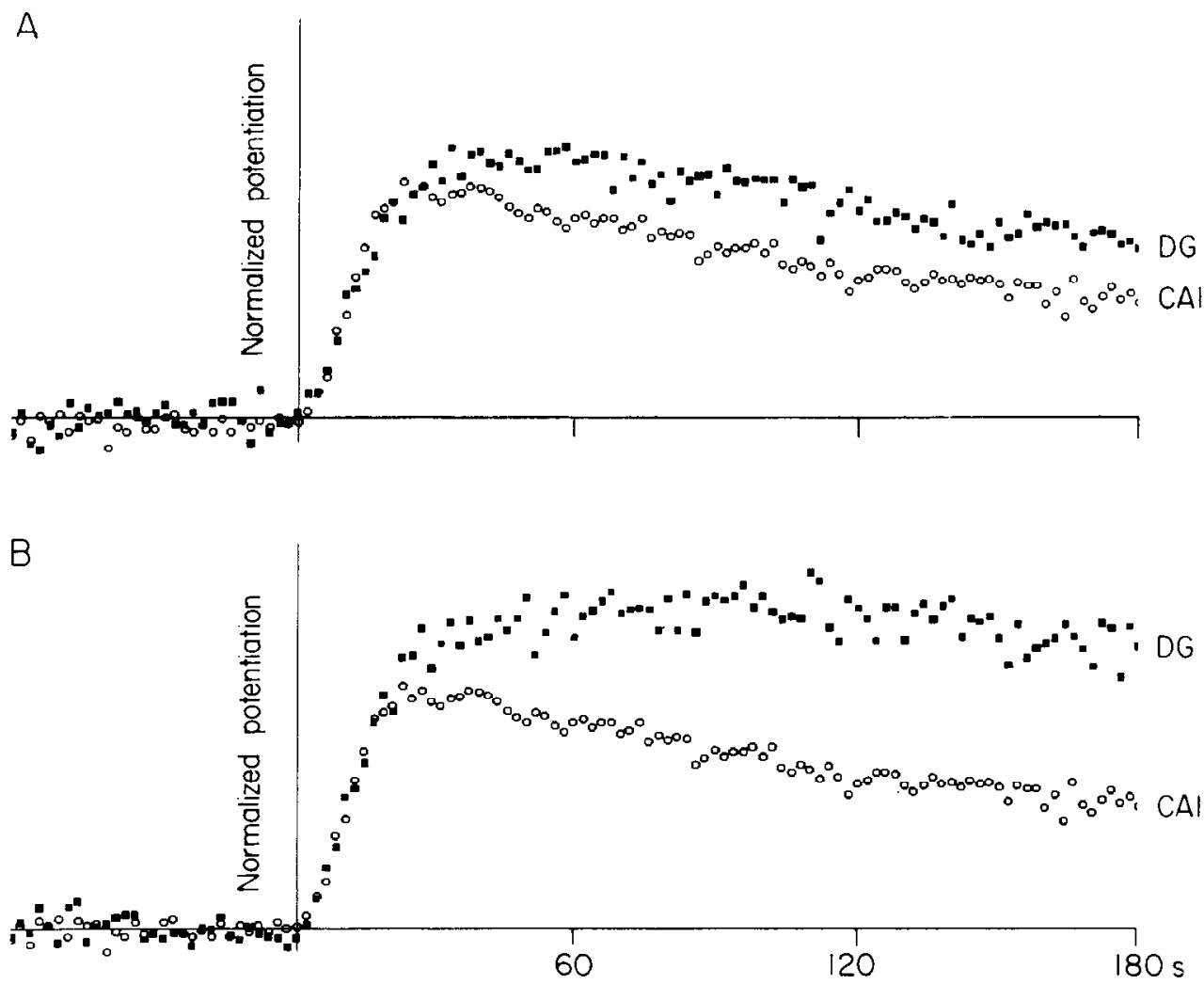

cluded by saturation of LTP for at least $1-2 \mathrm{hr}$ after tetanization (Gustafsson et al., 1989). Although one cannot exclude that such an occlusion is caused, for example, by a prolonged inactivation of the induction mechanism for the early potentiation, this result supports the idea of a common expression mechanism for LTP in the CA 1 region at least within the first 1 or $2 \mathrm{hr}$ (Gustafsson and Wigström, 1990). The present study in the dentate gyrus demonstrates a high degree of occlusion between the early, transient potentiation and LTP, suggesting that also in this region the induction event leads to a single type of synaptic modification that is not inherently stable, and that may stabilize to various degrees according to the induction conditions. This stabilization may in principle reflect a more intense activation of the same enzymatic system as that underlying the early phase, or reflect activation of another system with a higher induction threshold.

\section{Induction conditions controlling the stability of LTP}

In a model for LTP in the dentate gyrus, Linden and Routtenberg (1989) have emphasized the importance of presynaptic factors in the stabilization of LTP, presynaptic calcium influx during the tetanic activation increasing the stability of a presynaptically located LTP. The present results do not support such a model, at least not for the first hour of LTP. As shown presently, the presynaptic requirement for sustained LTP ( $>1$ $\mathrm{hr}$ ) is minimal since such LTP was evoked by only once pairing a single test EPSP with a brief tetanus to a separate set of afferents. At weak stimulation intensity, high-frequency afferent activation evoked LTP that decayed within half an hour, and increasing the number of afferent impulses did not result in more prolonged LTP, even though the amount of presynaptic calcium influx appeared to be increased as judged by the increased magnitude of augmentation (Zucker, 1989).

Instead, the main factor controlling the decay appeared to be the amount of postsynaptic activity and associated NMDA receptor activation during the LTP-inducing tetanization. By combining two weak tetani, by increasing stimulus intensity during tetanization, or by reducing postsynaptic inhibition (by picrotoxin) for a given stimulation intensity, the resulting potentiation changed from a transient to a stable form, and the same transformation took place when the concentration of the NMDA receptor antagonist APV was varied. It should be noted that these two drugs do not affect the presynaptic terminal as judged from the lack of effects on field EPSP slope, paired-pulse facilitation, frequency potentiation, and augmentation (Wigström and Gustafsson, 1985b; Wigström et al., 1986; Gustafsson et al., 1989). It has previously been shown that repetition of high-frequency stimulus trains at low frequency causes more prolonged LTP, a result that has been related to a greater enhancement of calcium accumulation in the presynaptic terminal for each train (Linden et al., 1987). As described in the Results, such stabilization of LTP may rather be due to the successively greater postsynaptic activity produced by each train. Thus, in conclusion, the results suggest that the stability of LTP in the dentate gyrus is critically related to the amount of postsynaptic calcium influx during the tetanus, and that presynaptic activity per se plays little role.

In view of this conclusion, it may seem surprising that longer afferent trains did not produce more stable LTP (compare above) since such trains would be expected to lead to more prolonged, and thus greater, postsynaptic calcium influx. However, due to the apparent frequency depression in the dentate gyrus (compare Figs. $5 B, 12 B 2, C 2$ ), these longer spike trains will presumably 
not cause more postsynaptic NMDA receptor activation than the shorter ones.

It should be noted that the present study used field EPSP recordings, reflecting events in a large population of synapses. The question then arises as to whether LTP at a single synapse decays and thereafter stabilizes, or whether the population response reflects a mixture of synaptic potentiations, some of which are transient and others morc or lcss stable. In the latter case, stronger induction, giving rise to a greater amount of calcium influx, would increase the proportion of synapses entering the stable, rather than the transient, state following the induction event. We can presently not distinguish between these two alternatives.

\section{Comparison between LTP in CA1 and in the dentate gyrus}

In the dentate gyrus, the initial growth phase of LTP was followed by a plateau or a period of slow growth for 1-2 min before a subsequent decay that was highly variable, depending on the induction strength. In contrast, LTP following a brief tetanus in the CAl region decays immediately and considerably after having reached its peak at the end of the initial growth phase (Gustafsson et al., 1989). This decay was fairly stereotyped and was not reduced by increased stimulus strength during the induction event, in contrast to the situation in the dentate gyrus. In further contrast, in the CAl region longer spike trains cause more stable LTP (Gustafsson et al., 1989; Malenka, 1991). This regional discrepancy in behavior of LTP may seem to indicate that postsynaptic activity does not play a similar decisive role in CA1 as suggested above for LTP in the dentate gyrus. However, experiments in the CAl region in which single test volleys were paired with depolarizing current pulses have indicated that also in this region the amount of postsynaptic activity is critical for the stabilization of LTP (Gustafsson et al., 1987; see also Malenka, 1991). This latter study (Malenka, 1991) also demonstrated, using longer spike trains, that (tetanus-induced) LTP duration depended on postsynaptic activity and NMDA receptor activation. The differences observed between the CAl region and dentate gyrus, when eliciting LTP by brief spike trains, may then suggest that the pre- and/or postsynaptic conditions required to obtain the optimal calcium influx are not the same in the two regions. Alternatively, they may reflect some difference in the biochemistrics underlying LTP in the two regions.

\section{Influence of stimulation pattern on LTP time course}

Previous studies have demonstrated that certain stimulus patterns, such as repetitive bursts of brief high-frequency trains (Greenstein et al., 1988), or tetanization at higher frequencies $(400 \mathrm{~Hz})$ rather than lower ones $(50$ and $100 \mathrm{~Hz}$ ) (Winson and Dahl, 1986), constitute a very efficient means to produce LTP in dentate gyrus. In the present study, we found no evident effect of using such stimulation patterns, repetitive burst stimulation producing potentiation that was no more stable than that given by a single train (with total equal number of impulses), and the $400 \mathrm{~Hz}$ tetanization producing potentiation that was no more stable than that following $100 \mathrm{~Hz}$ trains. However, in contrast to the previous studies, $\mathrm{GABA}_{\mathrm{A}}$-mediated inhibition was blocked in the present one. This suggests that the relative efficiency of certain stimulation patterns in evoking LTP is related to their modulation of the degree of postsynaptic inhibition during the induction event (Wigström and Gustafsson, 1985b; Pacelli et al., 1989), thus influencing the amount of postsynaptic activity critical for the calcium influx.

\section{Effect of depression on LTP time course?}

Lasting heterosynaptic depressions have been described in the dentate gyrus in vivo following afferent tetanization (Abraham and Goddard, 1983; Levy and Steward, 1983). It has in fact been suggested that a depression process occurs whenever there is sufficient postsynaptic activity to induce LTP, reducing the amount of LTP and creating a heterosynaptic depression (Hashemzadeh-Gargari et al., 1991). In the present study, a single strong tetanization gave rise to either no (Fig. 6), or only a transient (Fig. 3), heterosynaptic depression, also in inputs previously saturated with respect to LTP. Moreover, strong tetanization to such a saturated input gave no indication of a homosynaptic depression. These results suggest that the homosynaptically induced LTP presently described is not "contaminated" by a hidden depression process, unless this process also relies on NMDA receptor activation for its induction and develops and saturates in parallel with LTP. It can in this context be noted that in the CA1 region low-frequency stimulation (1$5 \mathrm{~Hz}$ ) can depress potentiated synaptic responses evoked at 0.05 $\mathrm{Hz}$ (Staubli and Lynch, 1990). This raises the possibility that the LTP presently described has been influenced by some depressive effect resulting from the relatively high test rate $(0.5$ $\mathrm{Hz}$ ) used. However, as shown, the early time course of LTP in the dentate gyrus was not different when using test rates of 0.05 $\mathrm{Hz}$ or $0.5 \mathrm{~Hz}$. This result may then point to a possible further difference in the regulation of LTP in the dentate gyrus and in the CAl region.

\section{Concluding remarks}

As noted in the introductory remarks, LTP in both the CAl region and the dentate gyrus is induced as a consequence of NMDA receptor activation. The present results demonstrate that the growth phase of LTP has the same temporal characteristics in the two regions, and that the relative degree of stabilization of LTP in the dentate gyrus, as in the CA1 region (Malenka, 1991), may be controlled by the amount of postsynaptic calcium influx during the induction event. Moreover, in both regions the early phase of LTP is largely occluded by saturation of the sustained component of LTP, suggesting a common expression mechanism for the early transient and the later sustained LTP components. Nevertheless, despite this overall similarity, there appears, as discussed above, to exist distinct differences with respect to the stabilization of LTP. It has also been reported that LTP in the CA 1 region attains a very stable level of potentiation after an initial 5-20 min decay phase (Diamond et al., 1988; Lynch et al., 1990; Malenka, 1991), in contrast to the situation in the dentate gyrus where even strong induction events led to LTP that continued to slowly decay throughout a $1 \mathrm{hr}$ recording period. What underlies this possible difference in behavior of LTP in the two regions is not clear from the present study. This apparently less stable LTP in the dentate gyrus seems, however, quite compatible with the suggestion by McNaughton and Barnes (1990) that the storage of information should be more temporary in the dentate gyrus than in the CAl region.

\section{References}

Abraham WC, Goddard GV (1983) Asymmetric relationships between homosynaptic long-term potentiation and heterosynaptic longterm depression. Nature 305:717-719.

Alonso A, de Curtis M, Llinás R (1990) Postsynaptic Hebbian and non-Hebbian long-term potentiation of synaptic efficacy in the en- 
torhinal cortex in slices and in the isolated adult guinea pig brain. Proc Natl Acad Sci USA 87:9280-9284.

Anwyl R, Mulkeen D, Rowan MJ (1989) The role of $N$-methyl-Daspartate receptors in the generation of short-term potentiation in the rat hippocampus. Brain Res 503:148-151.

Asztely F, Hanse E, Wigström H, Gustafsson B (1991) Synaptic potentiation in the hippocampal CAl region induced by application of $N$-methyl-D-aspartate. Brain Res 558:153-156.

Bliss TVP, Lömo T (1973) Long-lasting potentiation of synaptic transmission in the dentate area of the anaesthetized rabbit following stimulation of the perforant path. J Physiol (Lond) 232:331-356.

Bramham CR, Srebro B (1987) Induction of long-term depression and potentiation by low- and high-frequency stimulation in the dentate area of the anesthetized rat: magnitude, time course and EEG. Brain Res 405:100-107.

Dahl D, Burgard EC, Sarvey JM (1990) NMDA receptor antagonists reduce medial, but not lateral, perforant path-evoked EPSPs in dentate gyrus of rat hippocampal slice. Exp Brain Res 83:172-177.

Davies SN, Lester RAJ, Reymann KG, Collingridge GL (1989) Temporally distinct pre- and post-synaptic mechanisms maintain longterm potentiation. Nature 338:500-503.

Diamond DM, Dunwiddie TV, Rose GM (1988) Characteristics of hippocampal primed burst potentiation in vitro and in the awake rat. J Neurosci 8:4079-4088.

Errington ML, Lynch MA, Bliss TVP (1987) Long-term potentiation in the dentate gyrus: induction and increased glutamate release are blocked by $D(-)$ amino-phosphonovalerate. Neuroscience 20:279-284.

Greenstein YJ, Pavlides C, Winson J (1988) Long-term potentiation in the dentate gyrus is preferentially induced at theta rhythm periodicity. Brain Res 438:331-334.

Gustafsson B, Wigström H (1986) Hippocampal long-lasting potentiation produced by pairing single volleys and brief conditioning tetani evoked in separate afferents. J Neurosci 6:1575-1582.

Gustafsson B, Wigström H (1990) Basic features of long-term potentiation in the hippocampus. Semin Neurosci 2:321-333.

Gustafsson B, Wigström H, Abraham WC, Huang YY (1987) Longterm potentiation in the hippocampus using depolarizing current pulses as the conditioning stimulus to single volley synaptic potentials. J Neurosci 7:774-780.

Gustafsson B, Asztely F, Hanse E, Wigström H (1989) Onset characteristics of long-term potentiation in the guinea-pig hippocampal CA1 region in vitro. Eur J Neurosci 1:382-394.

Hanse E, Asztely F, Wigström H, Gustafsson B (1991) Long-lasting potentiations evoked by heterosynaptic tetani in the guinea pig dentate gyrus in vitro. Brain Res 555:173-176.

Harris EW, Cotman CW (1986) Long-term potentiation of guinea pig mossy fiber responses is not blocked by $N$-methyl-D-aspartate antagonists. Neurosci Lett 70:132-137.

Hashemzadeh-Gargari H, Colbert CM, Levy WB (1991) Refining the temporal definition of an association at the neuronal level using longterm potentiation and long-term depression in the dentate gyrus. Neurosci Lett 126:37-40.

Hess G, Gustafsson B (1990) Changes in the field excitatory postsynaptic potential shape induced by tetanization in the CAl region of the guinea-pig hippocampal slice. Neuroscience 37:61-66.

Kauer JA, Malenka RC, Nicoll RA (1988) NMDA application potentiates synaptic transmission in the hippocampus. Nature $324: 250$ 252.

Kennedy MB (1989) Regulation of synaptic transmission in the central nervous system - long-term potentiation. Cell 59:777-787.

Kuba K, Kumamoto E (1990) Long-term potentiations in vertebrate synapses: a variety of cascades with common subprocesses. Prog Neurobiol 34:197-296.

Lambert JDC, Jones RSG (1990) A reevaluation of excitatory amino acid-mediated synaptic transmission in rat dentate gyrus. J Neurophysiol 64:119-132.

Levy WB, Steward O (1983) Temporal contiguity requirements for long-term associative potentiation/depression in the hippocampus. Ncuroscience 8:791-797.
Linden DJ, Routtenberg A (1989) The role of protein kinase C in long-term potentiation: a testable model. Brain Res Rev 14:279-296.

Linden DJ, Sheu FS, Murakami K, Routtenberg A (1987) Enhancement of long-term potentiation by cis-unsaturated fatty acid: relation to protein kinase $C$ and phospholipase A2. J Neurosci 7:3783-3792.

Lömo T (1966) Frequency potentiation of excitatory synaptic activity in the dentate area of the hippocampal formation. Acta Physiol Scand 68:277-128.

Lynch G, Kessler M, Arai A, Larson J (1990) The nature and causes of hippocampal long-term potentiation. Prog Brain Res 83:233-250.

Magleby KL, Zengel JE (1976) Augmentation: a process that acts to increase transmitter release at the frog neuromuscular junction. $J$ Physiol (Lond) 257:449-470.

Malenka RC (1991) Postsynaptic factors control the duration of synaptic enhancement in area CA1 of the hippocampus. Neuron 6:5360 .

Malenka RC, Kauer JA, Perkel DJ, Nicoll RA (1989) The impact of postsynaptic calcium on synaptic transmission - its role in long-term potentiation. Trends Neurosci 12:444-450.

McNaughton BL (1980) Evidence for two physiologically distinct perforant pathways to the fascia dentata. Brain Res 199:1-19.

McNaughton BL (1982) Long-term synaptic enhancement and shortterm potentiation in rat fascia dentata act through different mechanisms. J Physiol (Lond) 324:249-262.

McNaughton BL, Barnes CA (1990) From cooperative synaptic enhancement to associative memory: bridging the abyss. Semin Neurosci 2:403-416.

McNaughton BL, Morris RGM (1987) Hippocampal synaptic enhancement and information storage within a distributed memory system. Trends Neurosci 10:408-415.

McNaughton BL, Douglas RM, Goddard GV (1978) Synaptic enhancement in fascia dentata: cooperativity among coactive afferents. Brain Kes 157:277-293.

Morris RG, Anderson E, Lynch GS, Baudry M (1986) Selective impairment of learning and blockade of long-term potentiation by an $N$-methyl-D-aspartate receptor antagonist, AP5. Nature 319:774-776.

Pacelli GJ, Su W, Kelso SR (1989) Activity-induced depression of synaptic inhibition during LTP-inducing patterned stimulation. Brain Res 486:26-32.

Sah P, Nicoll RA (1991) Mechanisms underlying potentiation of synaptic transmission in rat anterior cingulate cortex in vitro. J Physiol (Lond) 433:615-630.

Staubli U, Lynch G (1990) Stable depression of potentiated synaptic responses in the hippocampus with $1-5 \mathrm{~Hz}$ stimulation. Brain Res 513:113-118.

Teyler TJ, Alger BE (1976) Monosynaptic habituation in the vertebrate forebrain: the dentate gyrus examined in vitro. Brain Res 115:413425.

Teyler TJ, Discenna P (1984) Long-term potentiation as a candidate mnemonic device. Brain Res 319:15-28.

Wigström H, Gustafsson B (1985a) On long-lasting potentiation in the hippocampus: a proposed mechanism for its dependence on coincident pre- and postsynaptic activity. Acta Physiol Scand 123:159172.

Wigström H, Gustafsson B (1985b) Facilitation of hippocampal longlasting potentiation by GABA antagonists. Acta Physiol Scand 125: 159-172.

Wigström H, Gustafsson B, Huang Y-Y (1986) Mode of action of excitatory amino acid receptor antagonists on hippocampal long-lasting potentiation. Neuroscience 17:1105-1115.

Winson J, Dahl D (1986) Long-term potentiation in the dentate gyrus: induction by asynchronous volleys in separate afferents. Science 234 : 985-988.

Zalutsky RA, Nicoll, RA (1990) Comparison of two forms of longterm potentiation in single hippocampal neurons. Science 248:16191624

Zucker R (1989) Short-term synaptic plasticity. Annu Rev Neurosci 12:13-31. 